\title{
Modeling Photosynthesis of Row Crop Canopies
}

\author{
K.J. Boote ${ }^{1}$ and N.B. Pickering ${ }^{2}$ \\ Agronomy Department, University of Florida, Gainesville, FL 32611
}

Most field and horticultural crops are grown in rows rather than in horizontally uniform stands. Thus, it is important to be able to predict light interception and photosynthesis of incomplete hedgerow crops. With improved knowledge of the biochemistry of single-leaf photosynthesis, particularly in response to temperature and $\mathrm{CO}_{2}$ concentration, it is now possible to model canopy assimilation based on singleleaf characteristics.

The complexity of plant responses to climatic and management factors makes a mechanistic modeling approach attractive for predicting such responses reliably (Reynolds and Acock, 1985). Important plant processes include leaf photochemistry, leaf and canopy gas exchange, growth, and assimilate partitioning. Most efforts to model canopy photosynthesis mechanistically have applied only to closed horizontally uniform crop stands (Denison and Loomis, 1989; de Wit, 1965; Duncan et al., 1967; Norman and Arkebauer, 1991). Horticultural production could benefit from models that predict optimum spacing for fruit and nut tree crops, yield response to various hedgerow arrangements for trellised vineyards or staked tomatoes (Lycopersicon esculentum Mill.), and effects of various spacings on productivity of field and greenhouse commodities.

In this paper we describe a light interception-canopy photosynthesis approach that calculates absorption of direct and diffuse irradiance by incomplete hedgerow canopies as a function of canopy height, canopy width, leaf area index (LAI), leaf angle, row direction, latitude, day of year, and time of day. A sunlit and shaded LAI approach was used to simulate absorption of photosynthetic photon flux density (PFD) by sunlit and shaded leaves. Canopy assimilation is the sum of sunlit and shaded leaf photosynthesis over their respective LAI classes. Photosynthesis of sunlit and shaded leaves was computed with the asymptotic exponential equation, where quantum efficiency $\left(Q_{E}\right)$ and light-saturated photosynthesis rate $\left(\mathrm{P}_{\max }\right)$ were functions of intercellular $\mathrm{CO}_{2}\left(\mathrm{C}_{\mathrm{i}}\right), \mathrm{O}_{2}$, and temperature. The Farquhar and von Caemmerer equations for the ribulose 1,5 bisphosphate (RuBP)-regeneration limited region were used to compute the efficiency of electron conversion to $\mathrm{CO}_{2}$ fixation. The modeling approach is modular in that various mechanistic leaf photosynthesis equations can be substituted, with each receiving inputs of absorbed $\mathrm{PFD}$, temperature, and $\mathrm{CO}_{2}$ for each class of leaves.

\section{Light absorbance, reflectance, and transmittance processes}

Photosynthetically active irradiance arrives at leaf surfaces in crop canopies by several pathways: 1) direct beam, 2) diffuse skylight (scattered by atmosphere and clouds), 3) diffuse scattered from other foliage (e.g., reflected from and transmitted through foliage), and 4) diffuse scattered from the soil surface.

Green leaves have a high absorptance for photosynthetically active radiation. The leaf scattering coefficient for direct-beam irradiance ( $\sigma$ $=$ fraction transmitted plus reflected) is $\approx 0.20$ (Goudriaan, 1977), with $\approx 10 \%$ of incident PFD reflected, $\approx 10 \%$ transmitted, and $\approx 80 \%$ absorbed. The scattering coefficient varies somewhat with leaf thickness, leaf chlorophyll content, and angle of incidence of the direct

Florida Agricultural Experiment Station Journal Series no. R-03661. We express appreciation to H. Gijzen and J. Goudriaan for their excellent suggestions for adapting the sunlit leaf area index approach for hedgerow canopies. We thank J. Norman for his advice on the model and E.B. Blazey and G. Bourgeois for their assistance with photosynthesis measurements. The cost of publishing this paper was defrayed in part by the payment of page charges. Under postal regulations, this paper therefore must be hereby marked advertisement solely to indicate this fact.

${ }^{1}$ Professor of Agronomy. To whom reprint requests should be addressed.

${ }^{2}$ Visiting Assistant in Agricultural Engineering. beam. Scattering of direct-beam irradiance to lower leaves and penetration of diffuse skylight are important to canopy assimilation in two ways. First, in crop canopies, the lower, shaded leaves absorb $10 \%$ to $15 \%$ of the incident PFD that is scattered by the sunlit leaves. Second, lower leaves absorb a considerable fraction of the diffuse skylight since it is less directional than the direct beam. Diffuse-light flux absorbed by lower leaves, although fairly small, is important because, at low $\mathrm{PFD}$, the apparent $\mathrm{Q}_{\mathrm{E}}$ will be high for lower leaves.

\section{Light interception by closed crop canopies}

For crop canopies that are closed and have their leaves randomly distributed horizontally, there are simple equations for light interception and for PFD striking a leaf at any given LAI depth. Because the leaves in crop canopies are not contiguous, there are gaps between adjacent leaves through which light penetrates farther down in the canopy. Assuming the gaps are randomly distributed horizontally, the area of direct-beam irradiance penetrating to any depth in the canopy is an exponential function of the cumulative LAI from the top of the canopy (analogous to the Beer-Lambert law):

$\mathrm{I}=\mathrm{I}_{\mathrm{o}} \cdot \mathrm{e}\left(-\mathrm{K}_{\mathrm{d}} \cdot \mathrm{LAI}\right)$

where $I$ and $I_{0}$ are the total energies or areas of direct-beam fluxes on a horizontal plane at points within and above the canopy, respectively (Loomis and Williams, 1969; Monsi and Saeki, 1953). In the area context, the direct-beam extinction coefficient $\left(\mathrm{K}_{\mathrm{f}}\right)$ is the ratio of horizontally projected shadow area per unit land area per unit leaf area. The shadow projection of leaves depends on leaf angle and solar elevation angle $(\beta)$ from the horizontal. $K_{d}$ is 1.0 only when all leaves are distributed randomly in the horizontal plane and are perpendicular to the direct beam when the sun is directly overhead. Under these conditions, a canopy of $\mathrm{LAI}=1$ intercepts $63 \%$ of the incident direct irradiance. Since $K_{d}$ includes $1 / \sin (\beta)$, it varies as the solar elevation angle $\beta$ changes. Leaf angle variations also affect $\mathrm{K}_{\mathrm{d}}$ because less light is intercepted when leaves are displayed obliquely to the direct beam. Equation [1] assumes random horizontal distribution of leaf area; however, that assumption does not hold for incomplete row crop stands or regularly spaced but incomplete plant stands. In addition to $\mathrm{K}_{\mathrm{d}}$, total light extinction by a crop canopy requires accounting for scattering (reflectance and transmittance), as was done by Duncan et al. (1967) and Goudriaan $(1977,1982)$. For these reasons, experimentally determined values for total light extinction would not necessarily be the same as $\mathrm{K}_{\mathrm{d}}$ calculated from Eq. [1]. See Loomis and Williams (1969), Ross (1981), and Campbell and Norman (1989) for further information on light interception relative to leaf angle, leaf pattern, LAI, and solar elevation.

\section{Simple models for predicting assimilation of closed canopies}

Two simple models for gross canopy assimilation $\left(\mathrm{P}_{\text {can }}\right)$ of horizontally uniform canopies are introduced here, so readers can compare them to the subsequent hedgerow photosynthesis model. Both simple models use light-response curves that can be defined by $Q_{E}$ and $P_{\max }$. Acock et al. (1978) developed an analytical solution for $P_{c a n}$ that considers the integral of the Michaelis-Menten equation for leaf photosynthesis over successive LAI depth (L) as PFD is absorbed:

$\mathrm{P}_{\mathrm{can}}=\int_{0}^{\mathrm{LAI}} \mathrm{P}_{\text {leaf }} \mathrm{dL}$

Light attenuation through the canopy is assumed to follow the Beer-Lambert law, where $I_{0}$ is the PFD on a horizontal plane above the canopy. The actual PFD reaching the surface of a leaf and absorbed for 
photosynthesis $\left(\mathrm{I}_{\mathrm{i}}\right)$ at any LAI depth in the canopy requires consideration of $\sigma$ and $\mathrm{K}_{\mathrm{d}}$ (Charles-Edwards, 1981):

$I_{i}=K_{d} /(1-\sigma) \cdot I_{0} \cdot e^{\left(-K_{d} \cdot L A I\right)}$

$\mathrm{I}_{\mathrm{i}}$ is the average irradiance absorbed at any given LAI depth and does not reflect the randomness of sunflecks penetrating to depth in the canopy. Upon combining the Michaelis-Menten leaf light-response equation and Eq. [3] for PFD absorbed by leaf area at any LAI depth, then integrating over LAI depth, the following equation is obtained:

$P_{\text {can }}=\frac{P_{\max }}{K_{d}} \ln \frac{(1-\sigma) \cdot P_{\max }+Q_{E} \cdot K_{d} \cdot P F D}{(1-\sigma) \cdot P_{\max }+Q_{E} \cdot K_{d} \cdot P F D \cdot e\left(-K_{d} \cdot L A I\right)}$

Equation [4] tends to overpredict $\mathrm{P}_{\mathrm{can}}$ slightly, possibly because of the use of average irradiance per layer and because one $\mathrm{P}_{\max }$ value is used throughout the entire canopy. Reynolds et al. (1992) compared various model approaches and reported that using average irradiance for all leaves within a layer invariably overestimated canopy assimilation. This problem is inherent in the modeling approaches of Acock et al. (1978), Monsi and Saeki (1953), and Hirose and Werger (1987).

Another simple model for gross assimilation of closed crop canopies is based on the sunlit and shaded LAI approach and the exponential light-response equation (Boote and Jones, 1987; Boote and Loomis, 1991; Sinclair and Horie, 1989). This approach is based on light absorption by sunlit and shaded leaf classes, subsequent photosynthesis of these leaf classes, and summation of rates over the sunlit and shaded LAIs. The exponential light-response equation for leaf photosynthesis $(\mathrm{P})$ is described:

$\mathrm{P}=\mathrm{P}_{\max } \cdot\left[1-\mathrm{e}^{\left(-\mathrm{Q}_{\mathrm{E}} \cdot \mathrm{PFD} / \mathrm{P}_{\max }\right)}\right]$

First, consider photosynthesis by sunlit leaves. The amount of sunlit LAI ( $\mathrm{LAI}_{\text {sun }}$ ) is described analytically from $\mathrm{K}_{d}$ and total LAI (Goudriaan, 1977):

$\mathrm{LAI}_{\text {sun }}=\left(1 / \mathrm{K}_{\mathrm{d}}\right) \cdot\left[1-\mathrm{e}^{\left(-\mathrm{K}_{\mathrm{d}} \cdot \mathrm{LAI}\right)}\right]$

If $\mathrm{K}_{\mathrm{d}}=1$ (leaves perpendicular to solar beam), then sunlit LAI approaches 1 as LAI approaches infinity. If $K_{d}<1$, say 0.5 , then the amount of sunlit LAI would approach 2 as LAI approaches infinity. The incident PFD on $\mathrm{LAI}_{\text {sun }}$ would be $\mathrm{K}_{\mathrm{d}}$-PFD. After accounting for $\sigma$ due to reflectance and transmittance, the absorbed PFD would be (1 $\sigma) \cdot \mathrm{K}_{\mathrm{d}} \cdot \mathrm{PFD}$. Using the exponential leaf photosynthesis equation, the assimilation rate of sunlit leaves $\left(\mathrm{P}_{\text {sun }}\right)$ becomes

$\mathrm{P}_{\text {sun }}=\mathrm{P}_{\max } \cdot\left[1-\mathrm{e}^{\left(-\mathrm{Q}_{\mathrm{E}} \cdot \mathrm{K}_{\mathrm{d}} \cdot(1-\sigma) \cdot \mathrm{PFD} / \mathrm{P}_{\max }\right)}\right]$

Next, consider photosynthesis by shaded leaves. Total canopy photosynthesis is increased by the photosynthetic contribution of lower, shaded leaves that absorb diffuse skylight and direct beam scattered and transmitted through the upper leaves. Shaded LAI $\left(\mathrm{LAI}_{\mathrm{shd}}\right)$ is defined as any LAI that is not sunlit.

$\mathrm{LAI}_{\text {shd }}=\mathrm{LAI}-\mathrm{LAI}_{\text {sun }}$

In a typical situation, $\approx 10 \%$ to $20 \%$ of the direct beam is scattered through sunlit leaves to shaded leaves. In the simple examples in Boote and Loomis (1991), scattered direct beam $(\sigma=0.20)$ was assumed to include some diffuse skylight. As an approximation, Boote and Jones (1987) assumed that $\mathrm{LAI}_{\text {shd }}$ intercepted this scattered light using the same $\mathrm{K}_{\mathrm{d}}$ as for $\mathrm{LAI}_{\text {sun }}$, and that all shaded LAI shared equally in the use of this scattered PFD, once intercepted. Thus, PFD incident on, and available for, photosynthesis per unit shaded LAI $\left(\mathrm{PFD}_{\text {shd }}\right)$ is

$\mathrm{PFD}_{\text {shd }}=\sigma \cdot \mathrm{PFD} \cdot\left[1-\mathrm{e}^{\left(-\mathrm{K}_{\mathrm{d}} \cdot \mathrm{LAI}_{\text {shd }}\right)}\right] / \mathrm{LAI}_{\text {shd }}$

and assimilation by shaded leaves $\left(\mathrm{P}_{\text {shd }}\right)$ is

$P_{\text {shd }}=P_{\max } \cdot\left[1-e^{\left(-Q_{E} \cdot \text { PFD }_{\text {shd }} P_{\max }\right)}\right]$
The total canopy assimilation summed over both leaf categories is

$\mathrm{P}_{\text {can }}=\mathrm{P}_{\text {sun }} \cdot \mathrm{LAI}_{\text {sun }}+\mathrm{P}_{\text {shd }} \cdot \mathrm{LAI}_{\text {shd }}$

Given inputs of field measurements of leaf $\mathrm{P}_{\max }, \mathrm{K}_{\mathrm{d}}$, and LAI, the sunlit plus shaded LAI photosynthesis model has adequately predicted total canopy assimilation response to PFD measured on closed canopies of soybean (Glycine max L.), peanut (Arachis hypogaea L.), and common bean (Phaseolus vulgaris L.) (Boote and Jones, 1987; Boote et al., 1988). Predictions with the sunlit plus shaded LAI approach (Eqs. [6-11]) have generally been closer to observed total canopy photosynthesis than predictions with the analytical equation of Acock et al. (1978). The analytical equation (Eq. [4]) gives comparable, but slightly higher, predictions than the sunlit plus shaded LAI approach (same $\mathrm{K}_{\mathrm{d}}$ and $\sigma$ ). These two approaches are satisfactory for closed crop canopies but do not work well for incomplete hedgerow canopies and lack a separate accounting for interception of direct beam and diffuse skylight. The sunlit plus shaded LAI approach has the advantage that any leaf photosynthesis equation (simple or complex) can be used.

\section{Row crop canopies and nonrandom horizontal distribution of LAI}

Many field and horticultural crops are grown in rows and the foliage is confined within a hedgerow. Even under equidistant plant spacing, leaves are usually clumped about the main axis of the plant. The canopy leaf area is then nonrandomly distributed horizontally, allowing greater light capture in clumped regions and greater light penetration to the soil where gaps in the canopy exist. If one looks at the canopy hedgerows at midday with the sun directly overhead, the impression may be that considerable light is not captured. Nevertheless, the effects of time of day and day of year on solar elevation causes considerably greater capture for lower solar elevations. It is possible to simulate the light interception by a hedgerow using three-dimensional geometry if one considers hedgerow dimensions, latitude, day of year, and time of day (Allen, 1974; Boote and Loomis, 1991; Gijzen and Goudriaan, 1989; Mutsaers, 1980).

\section{ASSIMILATION BY HEDGEROW CANOPIES}

A model to predict assimilation of row crop canopies was developed by Boote et al. $(1988,1989)$ based on a simplification of the hedgerow approach of Gijzen and Goudriaan (1989). The approach considers sunlit and shaded LAI similar to that for a horizontally uniform canopy, but with adaptations that apply to hedgerows. A simplified version of this approach is described by Boote and Loomis (1991). The version described below is a component of our crop growth simulation model, CROPGRO (Hoogenboom et al., 1992).

\section{Canopy envelope and light extinction coefficients}

The crop model predicts plant height and width over time, as a function of rate of increase in vegetative stage (V; main stem node number) and internode length, which depends on temperature, water deficit, PFD, photoperiod, and plant vegetative stage (length per internode varies with $\mathrm{V}$ stage). Figure 1 illustrates prediction of width, height, and vegetative stage for a peanut crop canopy over the season. Plant canopy envelope is assumed to have an elliptical shape defined by the height and width. On an hourly basis, the shadow projected by individual plants is computed as a function of canopy height $(\mathrm{H})$, canopy width (W), time of day, day of year, latitude, and row azimuth. The shadow projections account for row spacing and spacing between plants in the row to allow computation of the fraction of the soil surface shaded by plant canopy at least once $\left(f_{\text {sh }}\right)$.

Solar azimuth and elevation are computed from standard equations as a function of latitude, day of year, and time of day (Spitters, 1986). Parameters such as latitude, row azimuth, row spacing, plant spacing in the row, leaf angle distribution, leaf scattering coefficient, soil albedo, and cultivar potential $\mathrm{P}_{\max }$ are assumed to remain constant during the season. Daily changes occur in day of year, height, width, $\mathrm{LAI}$, leaf $\mathrm{N}$ concentration, specific leaf weight, and actual $\mathrm{P}_{\max }$.

The direct-beam extinction coefficient, $\mathrm{K}_{\mathrm{d}}$, is computed hourly as 

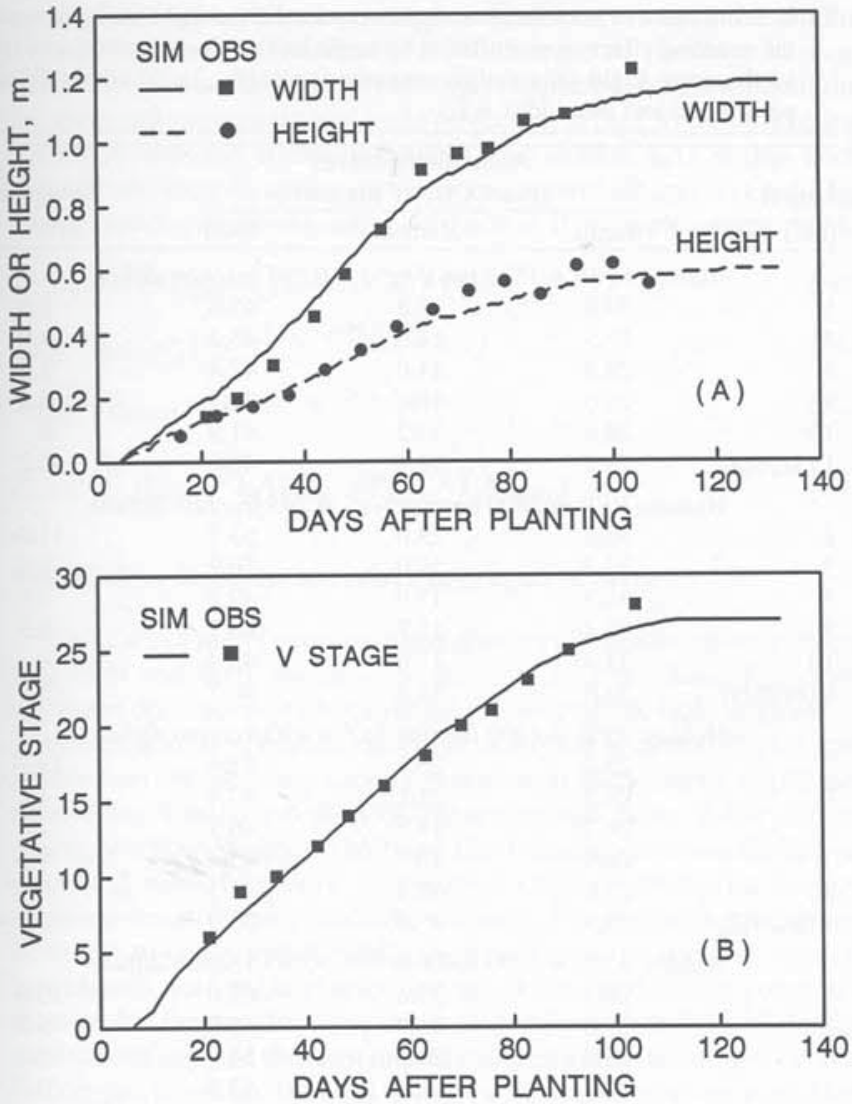

Fig. 1. (A) Predicted hedgerow width and height and (B) predicted vegetative stage of 'Florunner' peanut in 1990 at Gainesville, Fla. Solid points are field observations and line represents values simulated by PNUTGRO modelhedgerow version. $\mathrm{V}=$ vegetative.

a function of solar elevation and approximate leaf angle distribution among three angle classes ( 0 to 30,30 to 60 , and 60 to 90 degrees) using the approach of Goudriaan (1988). A similar, alternative approach has been proposed by Campbell and Norman (1989), whereby an ellipsoidal leaf angle distribution with a single parameter $(0.1=$ vertical, $10=$ horizontal) can be used to compute the proportion of leaves in each of three leaf angle classes. For simplicity, a spherical leaf-angle distribution could also be used, where the average horizontal projection of leaves relative to the direct-beam path is a constant 0.5 . Experience has shown that leaf angle distribution has only small effects on daily canopy photosynthesis, although a spherical leaf-angle distribution can underestimate light interception at midday for soybean and peanut. $\mathrm{K}_{\mathrm{d}}$ varies with $\beta$, because $\beta$ affects the effective pathlength through the canopy.

Light interception, photosynthesis, and LAI are restricted to the fraction of the soil surface shaded by the canopy $\left(\mathrm{f}_{\text {sh }}\right)$, which depends on overlapping shadows of plant ellipses relative to row spacing and plant spacing.

The sunlit and shaded LAI are computed for the hedgerow canopy as

$$
\begin{aligned}
& \mathrm{LAI}_{\text {sun }}=\left(\mathrm{f}_{\text {sh }} / \mathrm{K}_{\mathrm{d}}\right) \cdot\left[1-\mathrm{e}^{\left(-\mathrm{K}_{\mathrm{d}} \cdot \mathrm{LAI} / \mathrm{f}_{\text {sh }}\right)}\right] \\
& \mathrm{LAI}_{\text {shd }}=\mathrm{LAI}-\mathrm{LAI}_{\text {sun }}
\end{aligned}
$$

\section{Calculating hourly weather data}

Class A weather station data generally consist of daily maximum and minimum temperatures, daily rainfall, and, for a few stations, daily solar radiation and relative humidity. Hourly weather data are frequently not available, but can be used to drive the model if available. A function from Spitters (1986) is used to compute the hourly radiation values from daily values to distribute solar radiation and PFD throughout the day. Hourly temperatures are calculated from daily maximum and minimum air temperatures using a combined sine-exponential curve vs. time of day (Kimball and Bellamy, 1986; Parton and Logan, 1981). Hourly total and photosynthetic irradiance are split into direct $\left(\mathrm{PFD}_{\text {dir }}\right)$ and diffuse ( $\left.\mathrm{PFD}_{\text {dif }}\right)$ components using an algorithm for fraction diffuse vs. atmospheric transmission (Erbs et al., 1982; Spitters et al., 1986).

\section{Radiation absorption}

The PFD absorbed by sunlit and shaded LAI is computed as described by Spitters (1986). In this algorithm, a proportion of the direct-beam PFD is converted to diffuse within the canopy by scattering processes. The scattering coefficient $(\sigma)$ includes transmittance and reflectance down through the foliage. Reflectance $\left(\delta_{\text {dir }}\right.$ and $\left.\delta_{\text {dif }}\right)$ from the canopy to the sky depends on $\sigma$ and solar elevation. The use of $f_{\text {sh }}$ limits absorption of direct-beam PFD to the shaded soil surface area at any time of day. The relative LAI in the shaded zone is increased by dividing LAI by $\mathrm{f}_{\mathrm{sh}}$ as shown below:

$A_{\text {dir,dir }}=f_{\text {sh }} \cdot(1-\sigma) \cdot \operatorname{PFD}_{\text {dir }} \cdot\left[1-e^{\left(-K_{d} \cdot L A l / f_{\text {sh }}\right)}\right]$

$\left.\mathrm{A}_{\text {dir,tot }}=\mathrm{f}_{\text {sh }} \cdot\left(1-\delta_{\text {dir }}\right) \cdot \operatorname{PFD}_{\text {dir }} \cdot\left\{1-\mathrm{e}^{\left[-\mathrm{K}_{\mathrm{d}} \sqrt{(1-\sigma)}\right.} \cdot \mathrm{LAl} / \mathrm{f}_{\mathrm{sh}}\right]\right\}$

$\mathrm{A}_{\text {dir,dif }}=\mathrm{A}_{\mathrm{dir}, \text { tot }}-\mathrm{A}_{\mathrm{dir}, \mathrm{dir}}$

$\left.\delta_{\text {dif }}=[1-\sqrt{(1-\sigma)}] / 1+\sqrt{(1-\sigma)}\right]$

$\delta_{\text {dir }}=\delta_{\text {dif }} \cdot 2 /[1+1.6 \cdot \sin (\beta)]$

Absorption of diffuse skylight $\left(\mathrm{A}_{\text {dif }}\right)$ depends on row spacing $(R)$, plant spacing within the row (S), canopy height $(\mathrm{H})$, and canopy width (W), based on an adaptation of Goudriaan (1977). The approach computes the path width [gap $(\mathrm{G})$ between hedges $=\mathrm{R}-\mathrm{W}$ ] or the path width $(\mathrm{G})$ between plants in the row $(\mathrm{S}-\mathrm{W})$ to compute the view factor (fraction of sky seen by the plants) for incomplete canopies. A diffuse extinction coefficient of 0.8 is assumed.

If $\mathrm{W}<\mathrm{R}, \mathrm{G}=\mathrm{R}-\mathrm{W}$

DelR $=\mathrm{G}+\mathrm{H}-\sqrt{\left(\mathrm{G}^{* *} 2+\mathrm{H}^{* *} 2\right)}$

$\mathrm{f}_{\mathrm{r}}=\mathrm{MIN}[1.0,(\mathrm{~W}+\mathrm{DelR}) / \mathrm{R}]$

If $\mathrm{W}<\mathrm{S}, \mathrm{G}=\mathrm{S}-\mathrm{W}$

DelG $=\mathrm{G}+\mathrm{H}-\sqrt{\left(\mathrm{G}^{* *} 2+\mathrm{H}^{* *} 2\right)}$

$f_{p}=\operatorname{MIN}[1.0,(W+D e l G) / S]$

$\mathrm{A}_{\text {dif }}=\mathrm{ff}_{\mathrm{T}} \cdot\left(1-\delta_{\mathrm{dif}}\right) \cdot \mathrm{PFD}_{\mathrm{dif}} \cdot\left\{1-\mathrm{e}^{\left[-\mathrm{K}_{\mathrm{dif}} \sqrt{1-\sigma} \cdot \mathrm{LAL} /\left(\mathrm{f}_{\mathrm{f}} \cdot \mathrm{f}_{\mathrm{p}}\right)\right]}\right\}$

This approach assumes that diffuse irradiance originates from a uniformly overcast sky and that an incomplete canopy has a view factor $>1$. It is important that diffuse-light capture be computed in the two-dimensional manner above when plant canopy envelopes do not overlap within the row. This requirement was discovered by simulating single widely spaced plants, where, theoretically and in practice, photosynthesis and yield should reach a constant maximum per plant at some spacing at which single plants no longer compete for light.

Absorption of PFD reflected from soil $\left(\mathrm{A}_{\mathrm{ref}}\right)$ is handled in a similar manner to Eq. [25], based on total PFD incident on the soil surface (both direct and diffuse) and assuming that diffuse soil reflectance to $\operatorname{PFD}\left(\delta_{\text {soil }}\right)$ is 0.25 .

$\begin{aligned} \mathrm{PFD}_{\text {int }}= & \mathrm{A}_{\text {dir,dir }}+\mathrm{A}_{\text {dir,dif }}+\mathrm{A}_{\text {dif }}+\mathrm{f}_{\mathrm{sh}} \delta_{\text {dir }} \cdot \mathrm{PFD}_{\text {dir }}+ \\ & \mathrm{f}_{\mathrm{s}}, \delta_{\mathrm{p}} \bullet \delta_{\text {dif }} \cdot \mathrm{PFD}_{\text {dif }}\end{aligned}$

$\mathrm{PFD}_{\text {soil }}=\mathrm{PFD}-\mathrm{PFD}_{\text {int }}$

$\left.\left.\mathrm{A}_{\text {ref }}=\mathrm{f}_{\mathrm{r}} \mathrm{f}_{\mathrm{p}} \cdot\left(1-\delta_{\text {dif }}\right) \cdot \delta_{\text {soil }} \cdot \mathrm{PFD}_{\text {soil }} \cdot\left\{1-\mathrm{e}^{\left[-\mathrm{K}_{\text {dif }} \sqrt{(1-\sigma)}\right.} \cdot \mathrm{LAI} / \mathrm{f}_{\mathrm{f}} \mathrm{f}_{\mathrm{p}}\right)\right]\right\}[28]$

$\mathrm{PFD}_{\mathrm{abs}}=\mathrm{A}_{\text {dir,dir }}+\mathrm{A}_{\text {dir,dif }}+\mathrm{A}_{\text {dif }}+\mathrm{A}_{\text {ref }}$ 

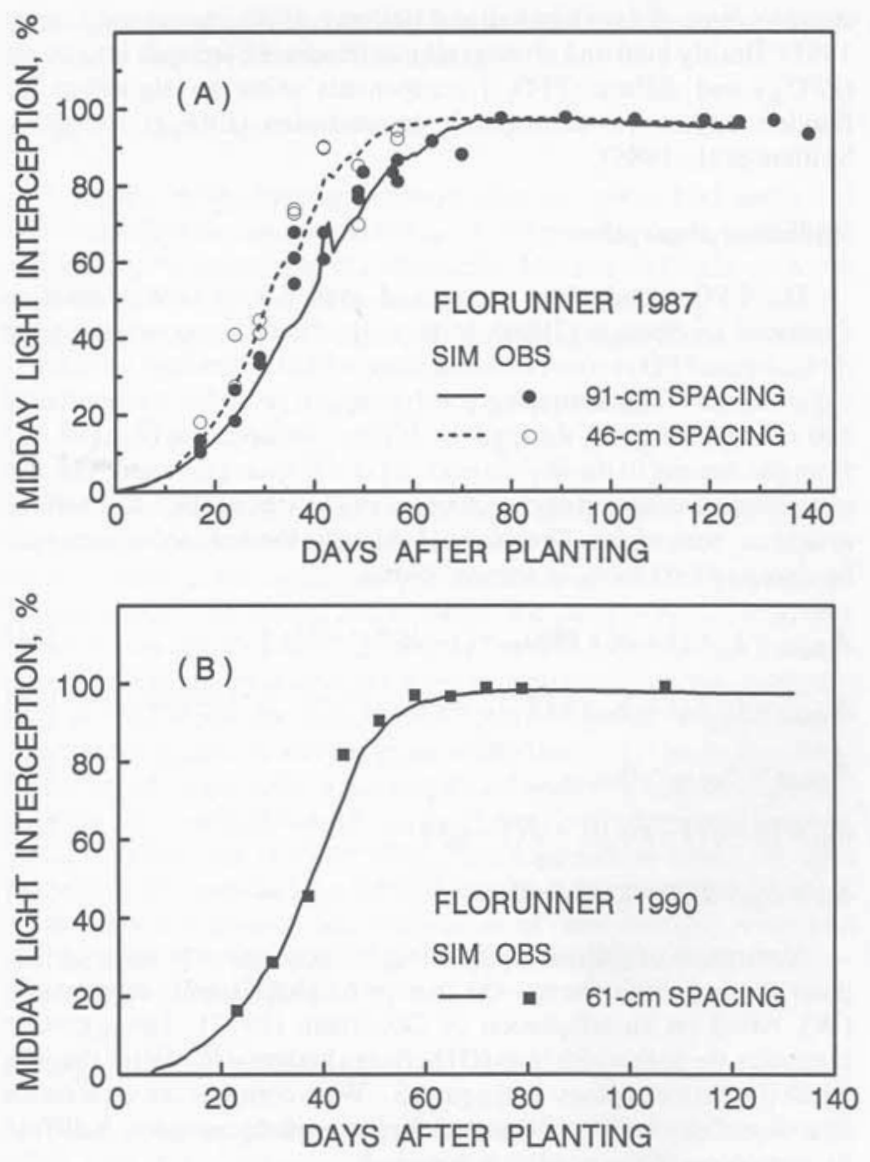

Fig. 2. Simulated and observed percent light interception at midday for 'Florunner' peanut canopies grown at Gainesville in (A) 46- and 91-cm row spacing in 1987 and (B) $61-\mathrm{cm}$ row spacing in 1990. Plant population was 22.4 plants $/ \mathrm{m}^{2}$ for both row spacings in 1987 , and 15 plants $/ \mathrm{m}^{2}$ in 1990 .

\section{Comparison to canopy light interception}

Canopy light absorption ( $\mathrm{PFD}_{\mathrm{abs}}$ ) is calculated in Eq. [29] as the sum of direct-beam PFD absorbed by sunlit leaves, direct beam converted to diffuse and absorbed by all LAI, skylight absorbed by sunlit and shaded leaves, and light reflected and absorbed from the soil. Canopy light interception $\left(\mathrm{PFD}_{\mathrm{int}}\right)$ is the sum of the first three components above and also includes reflectance of direct and diffuse from the canopy (Eq. [26]). Predicted and observed light interception is illustrated in Fig. 2 for peanut canopies with different row spacings. This figure illustrates that the hedgerow approach will predict light interception correctly if the geometry is adequately described (canopy height and width over time had been calibrated to field measurements).

\section{Allocation of diffuse PFD among LAI layers}

The PFD absorbed by the sunlit and shaded classes of leaves is computed for leaves in three LAI layers (each layer is one-third of total LAI). The flux of diffuse PFD absorbed by leaves in a given stratum, $\mathrm{PFD}_{\text {shd( })}$, is calculated from direct beam converted to diffuse within the canopy $\left(\mathrm{A}_{\text {dir,dif }}\right)$, absorbed skylight $\left(\mathrm{A}_{\text {dif }}\right)$, and diffuse reflected from the soil, applying Eqs. [14, 15, 16, 25, and 28] over one-third, two-thirds, and three-thirds of the total LAI, respectively, then using differences to calculate PFD absorbed per layer and per unit LAI in each layer. The average flux of PFD absorbed by the shaded leaves in a given stratum is $P_{\text {shd(i) }}$, whereas sunlit leaves additionally receive direct beam, $(1-\sigma) \cdot \mathrm{K}_{\mathrm{d}} \cdot \mathrm{PFD}_{\mathrm{dir}}$, as shown in Eq. [30].

The need for layering diffuse-light absorption was documented by Reynolds et al. (1992) and is also supported by our comparison of model predictions to field data. We found canopy assimilation to be overpredicted $10 \%$ to $15 \%$ when nonlayered diffuse-light capture was used for high LAI canopies and when the Spitters'(1986) fraction
Table 1. Influence of number of canopy layers for diffuse-light absorption and the resulting effect on assimilation by sunlit leaves, shaded leaves, and the total canopy. Light-saturated photosynthesis rate $\left(\mathrm{P}_{\max }\right)=26 \mu \mathrm{mol} \mathrm{CO} / \mathrm{m}^{2}$ per sec and leaf area index $=5$.

\begin{tabular}{|c|c|c|c|c|}
\hline \multirow{2}{*}{$\begin{array}{l}\text { Layers } \\
\text { (no.) }\end{array}$} & \multicolumn{3}{|c|}{$\begin{array}{c}\text { Assimilating leaves } \\
\left(\mu \mathrm{mol} \mathrm{CO} \mathrm{C}_{2} / \mathrm{m}^{2} \text { per sec }\right)\end{array}$} & \multirow{2}{*}{$\begin{array}{c}\text { Deviation } \\
(\%)\end{array}$} \\
\hline & Sunlit & Shaded & Total & \\
\hline \multicolumn{5}{|c|}{ Midday, $P F D^{z}=1500 \mu \mathrm{mol} \cdot \mathrm{m}^{-2} \cdot \mathrm{s}^{-1}, 0.245$ fraction diffuse } \\
\hline 1 & 27.8 & 17.8 & 45.6 & 8.9 \\
\hline 2 & 28.3 & 14.8 & 43.2 & 3.0 \\
\hline 3 & 28.5 & 14.0 & 42.4 & 1.4 \\
\hline 5 & 28.6 & 13.4 & 42.1 & 0.4 \\
\hline 10 & 28.6 & 13.2 & 41.9 & 0 \\
\hline $1(\mathrm{SL} / \mathrm{SH})^{y}$ & 29.2 & 11.4 & 40.6 & -3.2 \\
\hline \multicolumn{5}{|c|}{ Midday, $P F D=2000 \mu \mathrm{mol} \cdot \mathrm{m}^{-2} \cdot \mathrm{s}^{-1}, 0.245$ fraction diffuse } \\
\hline 1 & 30.7 & 23.0 & 53.7 & 11.0 \\
\hline 2 & 31.2 & 19.0 & 50.2 & 3.6 \\
\hline 3 & 31.3 & 17.9 & 49.2 & 1.6 \\
\hline 5 & 31.4 & 17.3 & 48.7 & 0.5 \\
\hline 10 & 31.4 & 17.0 & 48.4 & 0 \\
\hline $1(\mathrm{SL} / \mathrm{SH})$ & 31.8 & 14.8 & 46.7 & -3.7 \\
\hline \multicolumn{5}{|c|}{ Midday, $P F D=1500 \mu \mathrm{mol} \cdot \mathrm{m}^{-2} \cdot \mathrm{s}^{-1}, 0.490$ fraction diffuse } \\
\hline 1 & 25.0 & 26.5 & 51.5 & 13.7 \\
\hline 2 & 26.3 & 21.1 & 47.4 & 4.6 \\
\hline 3 & 26.7 & 19.5 & 46.2 & 2.0 \\
\hline 5 & 26.9 & 18.7 & 45.6 & 0.6 \\
\hline 10 & 27.0 & 18.4 & 45.3 & 0 \\
\hline $1(\mathrm{SL} / \mathrm{SH})$ & 28.3 & 15.6 & 43.9 & -3.0 \\
\hline \multicolumn{5}{|c|}{ Midday, $P F D=2000 \mu \mathrm{mol} \cdot \mathrm{m}^{-2} \cdot \mathrm{s}^{-1}, 0.490$ fraction diffuse } \\
\hline 1 & 28.4 & 33.6 & 62.0 & 16.6 \\
\hline 2 & 29.5 & 26.4 & 55.9 & 5.2 \\
\hline 3 & 29.8 & 24.6 & 54.3 & 2.2 \\
\hline 5 & 29.9 & 23.6 & 53.5 & 0.7 \\
\hline 10 & 30.0 & 23.2 & 53.2 & 0 \\
\hline $1(\mathrm{SL} / \mathrm{SH})$ & 31.2 & 20.2 & 51.4 & -3.3 \\
\hline
\end{tabular}

${ }^{2} \mathrm{PFD}=$ photon flux density.

${ }^{y} \mathrm{SL} / \mathrm{SH}$ assumes sunlit leaves over shaded leaves.

diffuse approach was followed. The overprediction was less pronounced on clear days and was minor in our earlier models in which we had arbitrarily limited the fraction of diffuse light and compared the models to data measured only on clear days (Boote et al., 1988, 1989). Reynolds et al. (1992) reported errors up to $15 \%$ when a single-layer model with one sunlit and one shaded leaf class was used, whereas a multilayer model with one sunlit and shaded leaf class per layer gave reasonable results. This finding indicates the need for layering LAI for diffuse-light absorption. We compared numbers of layers for diffuselight absorption (Table 1) and concluded that a model with three to five layers is adequate. A single-layer model (with sunlit and shaded leaves) gives $9 \%$ to $11 \%$ overprediction when the fraction of diffuse is low (0.245), but gives larger errors of $14 \%$ to $17 \%$ if the fraction of diffuse is higher. An assumption of sunlit leaves physically above shaded leaves for diffuse-light absorption underestimates $\mathrm{P}_{\mathrm{can}}$ by $3 \%$ to $4 \%$ compared to a 10 -layer model. Ignoring sunlit and shaded leaf classes in each LAI layer and computing average PFD absorbed per unit LAI was a poor option, giving a $0 \%$ to $19 \%$ higher estimate of $\mathrm{P}_{\text {can }}$ than versions with sunlit and shaded leaf classes. These results concur with those of Reynolds et al. (1992), who reported that modeling approaches using average irradiance for all leaves within a layer invariably overestimated canopy assimilation. We conclude that canopy assimilation models must have layering for diffuse PFD absorption and must have sunlit vs. shaded leaf classes. In our approach, the multilayer strategy is valuable primarily for diffuse-light absorption, because the sunlit leaves, by definition, receive direct beam regardless of canopy position. Layering has a minor effect on total PFD absorbed by sunlit leaves because the diffuse PFD on sunlit leaves varies by layer.

\section{Summation of canopy rate over sunlit and shaded leaves}

Leaf photosynthesis is computed with single-leaf equations, described below, for sunlit and shaded leaf classes within each of three canopy layers ( $\mathrm{i}=1$ to 3 ). Because using an average leaf projection 
angle slightly overestimates leaf photosynthesis, we use a three-point Gaussian approach (Goudriaan, 1986) to integrate photosynthesis of sunlit leaves over the range of leaf angles expected. For simplification, we show only a constant leaf angle projection in Eq. [30]. This layering approach requires computing sunlit and shaded LAI within each stratum and then summing up assimilation over all layers (Eq. [33]). Using layers also allows using variation in $\mathrm{P}_{\max (i)}$ with canopy depth.

$$
\begin{aligned}
& \mathrm{PFD}_{\text {sl(i) }}=\mathrm{PFD}_{\text {shd(i) }}+(1-\sigma) \cdot \mathrm{K}_{\mathrm{d}} \cdot \mathrm{PFD}_{\text {dir }} \\
& \mathrm{P}_{\text {sl(i) }}=\mathrm{P}_{\max (\mathrm{i})} \cdot\left\{1-\mathrm{e}^{\left[-\mathrm{Q}_{\mathrm{E}} \cdot \mathrm{PFD}_{\text {sl( } \left.(\mathrm{i} /)_{\max (i)}\right]}\right\}}\right. \\
& \mathrm{P}_{\text {shd(i) }}=\mathrm{P}_{\max (\mathrm{i})} \cdot\left\{1-\mathrm{e}^{\left[-\mathrm{Q}_{\mathrm{E}} \cdot \mathrm{PFD}_{\text {shd }(\mathrm{i})} \mathrm{P}_{\max (\mathrm{i})}\right]}\right\} \\
& \mathrm{P}_{\text {can }}=\sum_{\mathrm{i}=1}^{3}\left[\mathrm{P}_{\text {sun(i) }} \cdot \mathrm{LAI}_{\text {sun(i) }}+\mathrm{P}_{\text {shd(i) }} \cdot \mathrm{LAI}_{\text {shd(i) }}\right]
\end{aligned}
$$

\section{Use of class divisions to reduce aggregation error}

One cannot merely compute leaf photosynthesis rate at the average leaf PFD and then multiply by the total LAI to obtain $\mathrm{P}_{\text {can }}$. This approach does not work because the photosynthetic light response is nonlinear and most leaves are either at higher or lower PFD. Light penetration into the crop canopy is nonlinear with canopy depth and time of day. Rastetter et al. (1992) described this as the "fallacy of the averages" (from Wagner, 1969) and illustrated the problem nicely and discussed ways to reduce aggregation error in predicting canopy photosynthesis. We approach the nonlinear integration (aggregation) from leaf-to-canopy photosynthesis in several ways: sunlit vs. shaded leaf classes, leaf angle classes, canopy layers, and hourly computations within the day. In our opinion, the sunlit and shaded leaf classes (and time of day) are the most important aggregation techniques, while leaf-angle classes are the least important. Canopy layers are useful for diffuse-light absorption and allowing $\mathrm{P}_{\max }$ to vary with depth. In the terminology of Rastetter et al. (1992), we have primarily partitioned the fine-scale components into relatively homogeneous subaggregates with respect to $\mathrm{PFD}$ and $\mathrm{P}_{\max }$. We discussed the relative importance of these techniques for minimizing aggregation error in the previous section on allocation of diffuse PFD among LAI layers and in a subsequent section on variation in $\mathrm{P}_{\max }$, specific leaf weight (SLW), and $\mathrm{N}$ concentration with LAI depth.

\section{LEAF PHOTOSYNTHESIS EQUATIONS USED IN THE HEDGEROW MODEL}

\section{Equations for light response}

A common equation used for single-leaf photosynthesis response to light is the nonrectangular hyperbola given below, including parameters, $\mathrm{P}_{\max }, \mathrm{Q}_{\mathrm{E}}$, and a curvature factor $(\Theta)$ :

$$
\begin{aligned}
\mathrm{P}= & \left\{\mathrm{Q}_{\mathrm{E}} \cdot \mathrm{PFD}+\mathrm{P}_{\max }-\right. \\
& \left.\sqrt{\left[\left(\mathrm{Q}_{\mathrm{E}} \cdot \mathrm{PFD}+\mathrm{P}_{\max }\right)^{2}-4 \Theta \cdot \mathrm{Q}_{\mathrm{E}} \cdot \mathrm{PFD} \cdot \mathrm{P}_{\max }\right]}\right\} /(2 \Theta)
\end{aligned}
$$

Johnson and Thornley (1984) reviewed the use of the nonrectangular hyperbola for predicting photosynthetic response to PFD. When $\Theta=$ zero, the equation becomes a rectangular hyperbola (MichaelisMenten equation). With $\Theta=1.0$, the equation is a Blackman response of two intersecting straight lines. The asymptotic exponential equation (Eq. [5]) is similar to, but not exactly the same as, a nonrectangular hyperbola having a $\Theta$ of $\approx 0.7$. Most evidence suggests that the asymptotic exponential or a nonrectangular hyperbola with $\Theta=0.7$ to 0.9 provides a better fit than the Michaelis-Menten equation (Marshall and Biscoe, 1980; Peat, 1970). Evans and Farquhar (1991) used $\Theta=$ 0.7 to describe electron transport or photosynthesis response to PFD. The above equations are defined by initial slope, $Q_{E}$, and the asymptote ( $\mathrm{P}_{\max }$ at light saturation). Thus, it would be convenient if we could define environmental effects on $Q_{E}$ and $P_{\max }$.

\section{Incorporating leaf photosynthesis response to $\mathrm{CO}_{2}$ and temperature}

The Farquhar and von Caemmerer (1982) approach is commonly used to predict leaf photosynthetic response to $\mathrm{C}_{\mathrm{i}}$. In their model, leaf $\mathrm{CO}_{2}$ assimilation rate takes the minimum of two equations: 1) rubiscolimiting equation (primarily at low $\mathrm{C}_{\mathrm{i}}$, where $\mathrm{CO}_{2}$ assimilation responds almost linearly to increasing $\mathrm{C}_{\mathrm{i}}$ and rate is limited by rubisco activity), and 2) RuBP-limiting equation (at ambient to superambient $\mathrm{C}_{\mathrm{i}}$, where assimilation responds less rapidly to increasing $\mathrm{C}_{\mathrm{i}}$ because rate is limited by electron transport). We use an adaptation based only on the RuBP-limiting equations for several reasons. First, the transition to the RuBP-limiting region begins near ambient $\mathrm{CO}_{2}$ and continues to higher $\mathrm{CO}_{2}$ levels. We are primarily interested in predictions only at and above ambient $\mathrm{CO}_{2}$. Second, assimilation in crop canopies is limited by light availability during much of the day, and lower parts of the crop canopy are light-limited all the time; thus, the RuBPlimiting equations apply more often. Last, our approach eliminates the need for independent estimates of the rubisco's maximum rate and its Michaelis constants.

In our hedgerow canopy photosynthesis model, we predict $\mathrm{Q}_{\mathrm{E}}$ as a function of $\mathrm{CO}_{2}, \mathrm{O}_{2}$, and temperature, while $\mathrm{P}_{\max }$ is modeled as a function of $\mathrm{CO}_{2}, \mathrm{O}_{2}$, temperature, SLW, and $\mathrm{N}$ concentration. In our approach, $\mathrm{CO}_{2}, \mathrm{O}_{2}$, and temperature effects on $\mathrm{Q}_{\mathrm{E}}$ and $\mathrm{P}_{\max }$ follow the approach of Farquhar and von Caemmerer (1982), assuming that RuBP is limiting; this includes the temperature effects on specificity factor $(\tau)$ and $\mathrm{CO}_{2}$ compensation point $\left(\Gamma^{*}\right)$ in absence of mitochondrial respiration.

Under limiting low light, where $Q_{E}$ is defined, the Farquhar and von Caemmerer (1982) equations, assuming electron transport is limiting, approach the limit of

$\mathrm{Q}_{\mathrm{E}}=\frac{\left(\mathrm{C}_{\mathrm{i}}-\Gamma^{*}\right)}{4 \mathrm{C}_{\mathrm{i}}+8 \Gamma^{*}} \cdot \frac{1}{2.1}$

where the latter part of the equation (1/2.1) represents 1 electron per 2.1 photons, and the first part of the equation is the efficiency of using electrons to fix and reduce $\mathrm{CO}_{2}$. This limiting equation for $\mathrm{Q}_{\mathrm{E}}$ is equation 16.63 of Farquhar and von Caemmerer (1982), assuming electron transport is limiting. At light saturation, the same equation holds for efficiency of using electrons for $\mathrm{CO}_{2}$ assimilation:

$\mathrm{Q}_{\mathrm{E}}=\frac{\left(\mathrm{C}_{\mathrm{i}}-\Gamma^{*}\right)}{4 \mathrm{C}_{\mathrm{i}}+8 \Gamma^{*}} \cdot \frac{1}{\mathrm{QR}_{\mathrm{sat}}}$

Fewer electrons, however, are produced per photon absorbed $\left(1 / \mathrm{QR}_{\text {sat }}\right)$. In a practical sense, $1 / \mathrm{QR}_{\text {sat }}$ is related to the light-saturated rate of electron transport, $\mathrm{J}_{\max }$.

Equations [35] and [36] essentially describe the efficiency of electron use for $\mathrm{CO}_{2}$ fixation, from zero to saturating PFD. To calculate the effect of $\mathrm{CO}_{2}$ and temperature on $\mathrm{Q}_{\mathrm{E}}$, we use Eq. [35] with a scalar of 6.225 to compute a relative effect, $\mathrm{CO}_{2} \mathrm{Q}_{\mathrm{E}}(1.0$ at $30 \mathrm{C}$ and $350 \mathrm{ppm})$. $\mathrm{CO}_{2} \mathrm{Q}_{\mathrm{E}}$ is then multiplied by 0.0541 ( $\mathrm{mol} \mathrm{CO}_{2}$ fixed/mol PFD), which is the $\mathrm{Q}_{\mathrm{E}}$ (adjusted from 0.0524 at $325 \mathrm{ppm} \mathrm{CO}_{2}$ ) from observations on many $C_{3}$ species (Ehleringer and Björkman, 1977; Ehleringer and Pearcy, 1983).

$$
\mathrm{CO}_{2} \mathrm{Q}_{\mathrm{E}}=6.225 \cdot \frac{\left(\mathrm{C}_{\mathrm{i}}-\Gamma^{*}\right)}{4 \mathrm{C}_{\mathrm{i}}+8 \Gamma^{*}}
$$

$\mathrm{Q}_{\mathrm{E}}=0.0541 \cdot \mathrm{CO}_{2} \mathrm{Q}_{\mathrm{E}}$

To compute $\Gamma^{*}$ and $\mathrm{C}_{\mathrm{i}}$, we need to know $\tau$, the specificity factor of rubisco for $\mathrm{CO}_{2}$ vs. $\mathrm{O}_{2}$. Harley and Tenhunen (1991) used the following exponential energy of activation equation to describe the response of $\tau$ to temperature based on data of Jordan and Ogren (1984):

$\tau=\exp \{-3.9489+28990 /[8.31($ TEMP +273$)]\}$

The $\tau$ value decreases and $\Gamma^{*}$ increases similarly with temperature for most $\mathrm{C}_{3}$ species (Brooks and Farquhar, 1985; Jordan and Ogren, 1984). Then $\Gamma^{*}$ can be computed as a function of $\mathrm{O}_{2}$ concentration $\left(0.21 \mathrm{~mol} \cdot \mathrm{mol}^{-1}\right)$ and $\tau$ :

$\Gamma^{*}=1000000 \cdot 0.5 \cdot 0.21 / \tau$ 


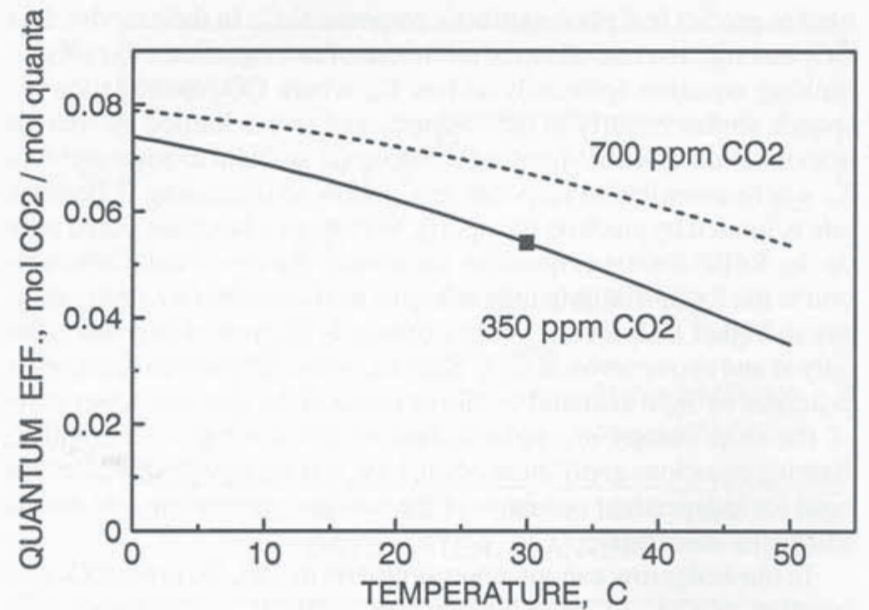

Fig. 3. Predicted quantum efficiency $\left(\mathrm{Q}_{\mathrm{E}}\right)$ at $\mathrm{CO}_{2}$ concentration of 350 and 700 $\mathrm{ppm}$ as affected by temperature. Point represents reference $\mathrm{Q}_{\mathrm{E}}$ of 0.0541 at $350 \mathrm{ppm} \mathrm{CO}{ }_{2}$ based on Ehleringer and Björkman (1977).

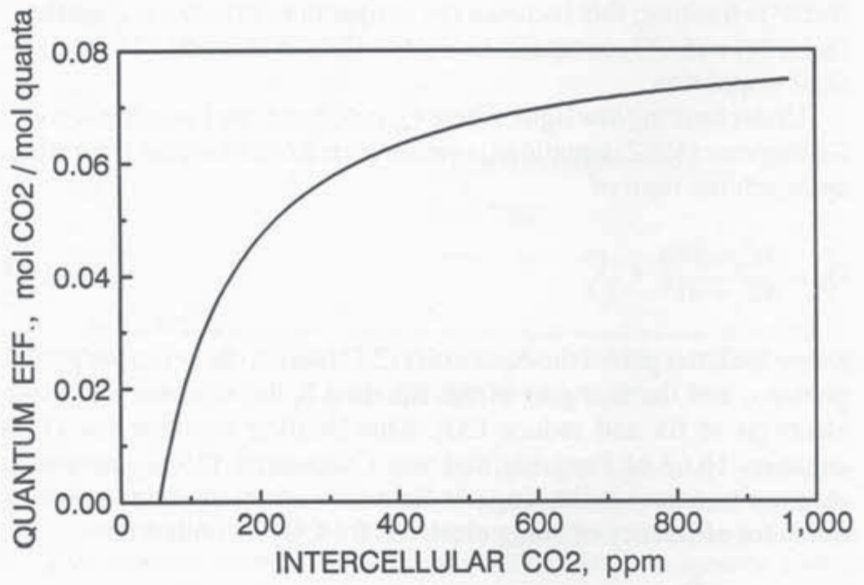

Fig. 4. Predicted quantum efficiency $\left(Q_{E}\right)$ at $30 \mathrm{C}$ as affected by $\mathrm{CO}_{2}$ concentration.

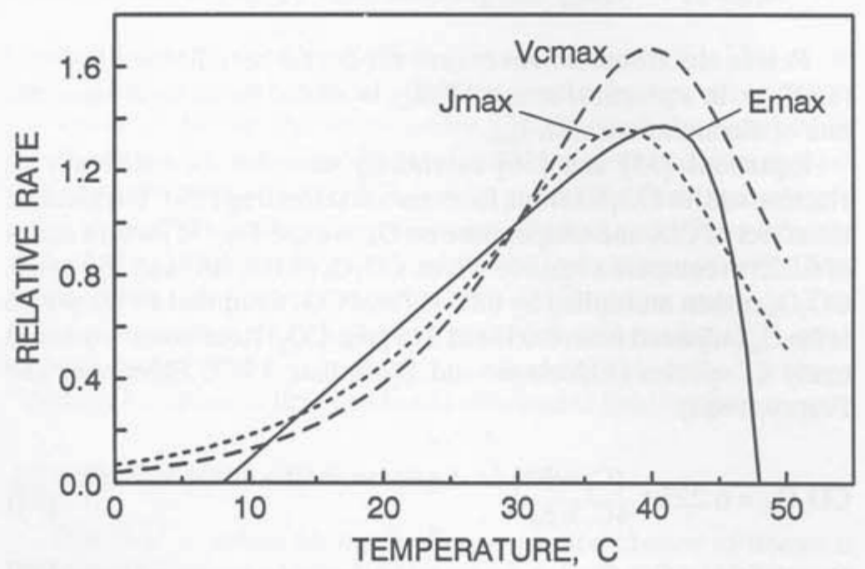

Fig. 5. Relative rate of electron transport $\left(\mathrm{E}_{\max }\right)$ vs. temperature. $\mathrm{J}_{\max }$ and $\mathrm{V}_{\mathrm{cmax}}$ are electron transport and rubisco rate from Harley et al. (1985). All responses are normalized to 1.0 at $30 \mathrm{C}$.

Equation [36] is used to describe $C_{i}$ and temperature effects on the relative efficiency of $\mathrm{CO}_{2}$ fixation $\left(\mathrm{CO}_{2 \max }\right)$ in saturating light (at $\left.\mathrm{P}_{\max }\right)$ as follows:

$\mathrm{CO}_{2 \max }=7.179 \cdot \frac{\left(\mathrm{C}_{\mathrm{i}}-\Gamma^{*}\right)}{\left(4 \mathrm{C}_{\mathrm{i}}+8 \Gamma^{*}\right)}$

Equation [41] is scaled to a relative effect of 1.0 at $30 \mathrm{C}$ and 350 $\mathrm{ppm} \mathrm{CO}_{2}$. This requires $\mathrm{P}_{\max }$ input to the model to be described as $\mathrm{CO}_{2}$ fixation rate measured at saturating PFD, $30 \mathrm{C}, 350 \mathrm{ppm} \mathrm{CO}_{2}$, and $21 \% \mathrm{O}_{2}$.

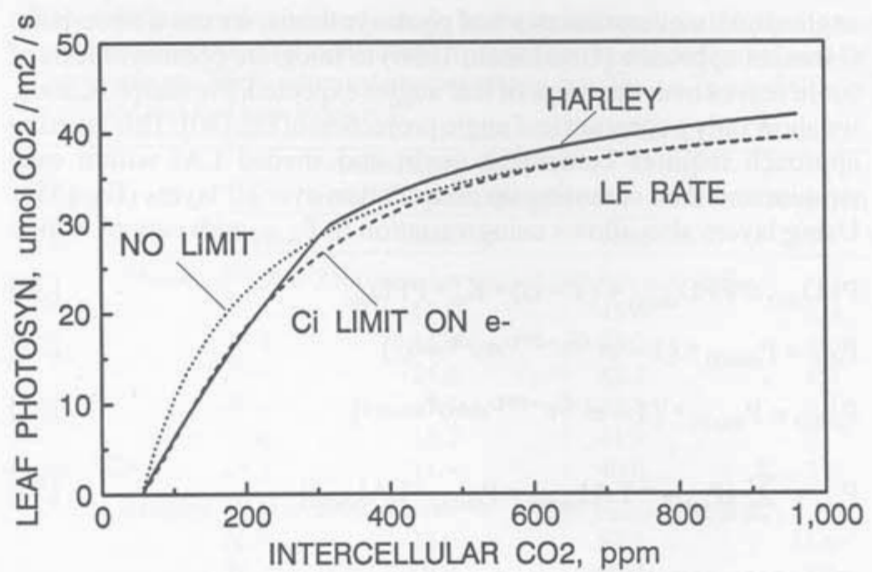

Fig. 6. Leaf photosynthesis response to intercellular $\mathrm{CO}_{2}\left(\mathrm{C}_{\mathrm{i}}\right)$ with and without $\mathrm{CO}_{2}$-substrate limitations on electron transport. Simulated at $30 \mathrm{C}$ and a photon flux density of $1500 \mu \mathrm{mol} \cdot \mathrm{m}^{-2} \cdot \mathrm{s}^{-1}$ using light-saturated photosynthesis rate $\left(\mathrm{P}_{\max }\right)=28 \mu \mathrm{mol} \mathrm{CO} / \mathrm{m}^{2}$ per sec. Harley equation was parameterized as described by Harley et al. (1985).

At the light compensation point, $\mathrm{C}_{\mathrm{i}}$ is assumed equal to $\mathrm{C}_{\mathrm{a}}$. In contrast, at high PFD, $\mathrm{C}_{\mathrm{i}}$ is computed with the following equation, where the ratio of 0.7 is the rate of change of $C_{i}$ with respect to $C_{a}$, which has held over a wide range of environmental conditions for many $\mathrm{C}_{3}$ species (Morison, 1987).

$\mathrm{C}_{\mathrm{j}}=0.7 \mathrm{C}_{\mathrm{a}}+0.3 \Gamma^{*}$

The $\mathrm{Q}_{\mathrm{E}}$ response to temperature and $\mathrm{CO}_{2}$, based on Eqs. [35-40], is shown in Figs. 3 and 4 . The responses closely mimic the sensitivity of $\mathrm{Q}_{\mathrm{E}}$ to temperature and $\mathrm{CO}_{2}$ reported for $\mathrm{C}_{3}$ species by Ehleringer and Björkman (1977). The shape of $\mathrm{CO}_{2 \max }$ vs. temperature and $\mathrm{CO}_{2}$ is very similar, but is normalized to 1.0 at $30 \mathrm{C}$ and $350 \mathrm{ppm} \mathrm{CO}_{2}$.

\section{Effect of temperature on $\mathbf{J}_{\max }$}

The $\mathrm{CO}_{2 \max }$ equation essentially describes the relative efficiency of converting electrons to $\mathrm{CO}_{2}$ fixed at high light intensity as influenced by $\mathrm{C}_{\mathrm{i}}, \mathrm{O}_{2}$, and temperature, but does not address temperature effects on electron transport itself. Temperature effects on light-saturated, $\mathrm{CO}_{2}$ saturated leaf photosynthesis of soybean have been described with energy of activation-deactivation equations by Harley et al. (1985) and Harley and Tenhunen (1991). Since responses obtained by Harley et al. (1985) for soybean and by Tenhunen et al. (1976) for common bean (Phaseolus vulgaris L.) were almost linear and there were no data below $15 \mathrm{C}$, we used a straight line function, shown in Fig. 5, for increasing electron transport between 8 and $40 \mathrm{C}$, scaled to a relative value of 1.0 at 30C (Pickering et al., 1995). Exponentially increasing heat damage to photosystem II is assumed, which reduces the rate $1.5 \%$ at $36 \mathrm{C}, 6 \%$ at $40 \mathrm{C}, 25 \%$ at $44 \mathrm{C}$, and $100 \%$ (to zero) at $48 \mathrm{C}$. Figure 5 compares our combined function to that of Harley et al. (1985).

\section{Effect of $\mathrm{CO}_{2}$ on electron transport}

If electron acceptors become limiting, as when $\mathrm{CO}_{2}$ declines below ambient, then electron transport is decreased because of inadequate $\mathrm{CO}_{2}$ or $\mathrm{O}_{2}$ to be fixed. Electron transport of $P$. vulgaris in high light flux (PFD $>380 \mu \mathrm{mol} \cdot \mathrm{m}^{-2} \cdot \mathrm{s}^{-1}$ ) was reported to decrease as $\mathrm{C}_{\mathrm{i}}$ fell below 300 $\mathrm{ppm} \mathrm{CO}_{2}$, but there was no $\mathrm{C}_{1}$ effect at a PFD of $175 \mu \mathrm{mol} \cdot \mathrm{m}^{-2} \cdot \mathrm{s}^{-1}$ (Sharkey et al., 1988). The authors explained this as the regulation of electron transport to match the rate of rubisco activity at low $C_{i}$ in the presence of high PFD. The excess energy was lost as chlorophyll fluorescence. Applying RuBP-limited equations to data on rice (Oryza sativa L.) canopy assimilation at 160 to $900 \mathrm{ppm} \mathrm{CO}_{2}$ and solving for $\mathrm{P}_{\max }$ showed that $\mathrm{P}_{\max }$ declined as $\mathrm{C}_{\mathrm{a}}$ dropped below 330 or $500 \mathrm{ppm}$ (Boote et al., 1992).

To address this problem, we added an asymptotic equation $\left[1-e\left(-z^{*} C_{i}\right)\right]$ that decreases $\mathrm{P}_{\max }$ as a function of $\mathrm{C}_{\mathrm{i}}$. This term describes substrate limitation for electron transport-RuBP generation. The $50 \%$ response 
level was reached between $\mathrm{C}_{\mathrm{i}}=83$ to $137 \mathrm{ppm}$ for rice. This function accounts for the effects of the rubisco-limited phase in a simple way that is normalized to the original $\mathrm{P}_{\max }$ term. As illustrated in Fig. 6, this causes a sharper transition in response to $\mathrm{CO}_{2}$ than our original function, but gives an $\mathrm{A}: \mathrm{C}_{\mathrm{i}}$ curve that is more similar to the Farquhar and von Caemmerer approach [as parameterized by Harley et al. (1985)].

\section{Leaf and canopy photosynthesis response to temperature}

Leaf response to temperature. Despite a linear effect of temperature on $\mathrm{J}_{\max }$, leaf photosynthesis response to temperature shows a curvilinear trend with a broad optimum, even at high $\mathrm{CO}_{2}$ and a PFD of $1500 \mu \mathrm{mol} \cdot \mathrm{m}^{-2} \cdot \mathrm{s}^{-1}$ (Fig. 7A). At ambient $\mathrm{CO}_{2}(350 \mathrm{ppm})$, the response becomes flatter, with broad optimum between 32 and $40 \mathrm{C}$. The leaf $\mathrm{P}$ response to $\mathrm{CO}_{2}$ increases with temperature.

Canopy response to temperature. Simulated instantaneous canopy photosynthesis is illustrated in Fig. 7B for a closed canopy at solar noon $\left(\mathrm{LAI}=5.0, \mathrm{PFD}=1500 \mu \mathrm{mol} \cdot \mathrm{m}^{-2} \cdot \mathrm{s}^{-1}\right.$ on $1 \mathrm{July}$ at lat. $\left.30^{\circ} \mathrm{N}\right)$. Note that the optimum temperature for photosynthesis is quite broad, between 25 to $37 \mathrm{C}$ at $350 \mathrm{ppm} \mathrm{CO}$, but the optimum temperature increases as $\mathrm{CO}_{2}$ concentration increases. The broad temperature optimum for $\mathrm{P}_{\text {can }}$ at ambient $\mathrm{CO}_{2}$ is caused by two features: 1) in a canopy, many leaves operate at low light flux, which increases the effect of $Q_{E}$, and 2) leaf photosynthesis depends on temperature functions that influence $Q_{E}$ and $P_{\max }$, and these two temperature functions operate in opposite directions. Using similar modeling approaches, Long (1991) also found broad optimums for daily $\mathrm{P}_{\text {can }}$ that shifted up several degrees with $\mathrm{CO}_{2}$ enrichment. The broad temperature optimum for $\mathrm{P}_{\mathrm{can}}$ is consistent with field data showing little variation on crop growth rates despite variation in air temperature. It
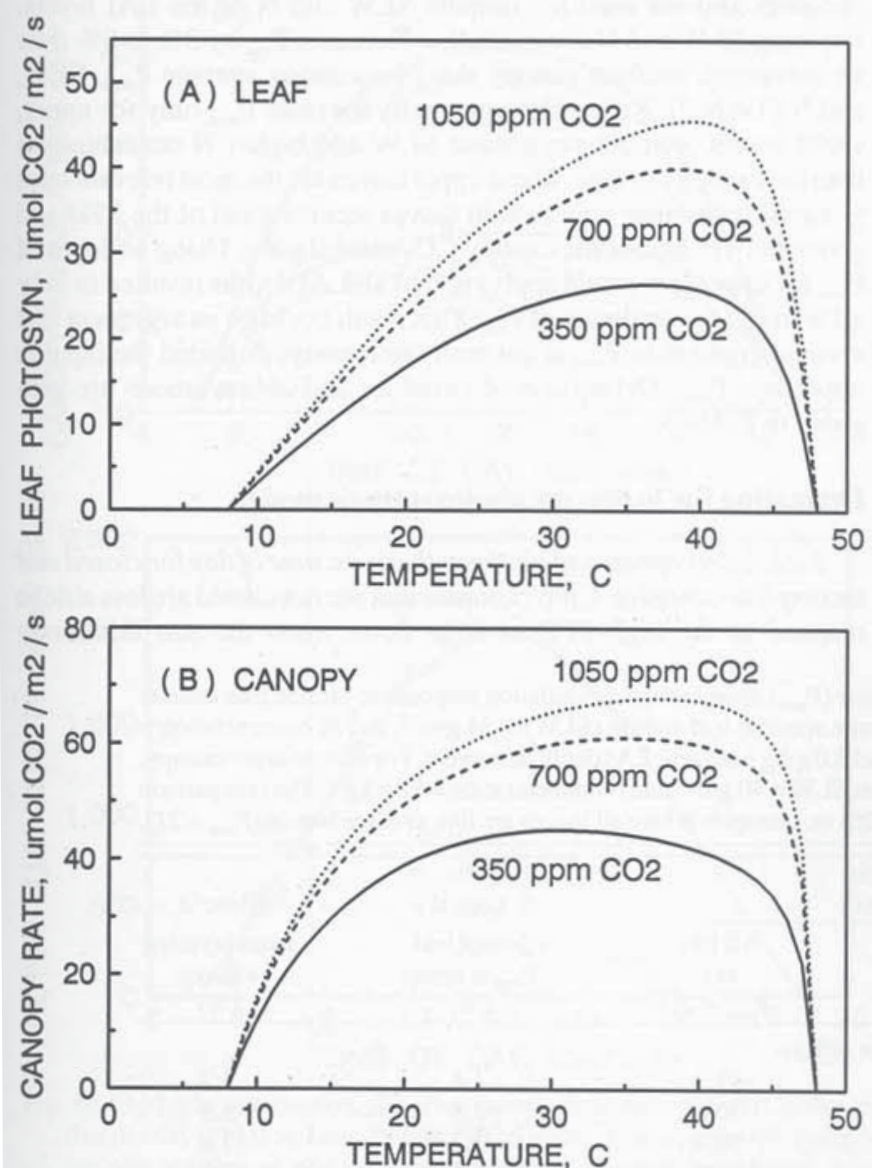

Fig. 7. (A) Leaf photosynthesis and (B) gross canopy assimilation $\left(\mathrm{P}_{\mathrm{can}}\right)$ response to leaf temperature at three $\mathrm{CO}_{2}$ concentrations. Response simulated for leaf area index $=5.0$, closed canopy, at a photon flux density of $1500 \mu \mathrm{mol} \cdot \mathrm{m}^{-2} \cdot \mathrm{s}^{-1}$, at solar noon on $1 \mathrm{July}$ at lat. $30^{\circ} \mathrm{N}$, assuming fraction diffuse of 0.49. Light-saturated photosynthesis rate $\left(\mathrm{P}_{\max }\right)=26 \mu \mathrm{mol} \mathrm{CO} /$ $\mathrm{m}^{2}$ per $\mathrm{sec}$ at $350 \mathrm{ppm} \mathrm{CO}$ and $30 \mathrm{C}$. is also supported by measurements in sunlit controlled-environment chambers, which showed no difference in $\mathrm{P}_{\text {can }}$ for rice at air temperatures of 25 to $37 \mathrm{C}$ (Baker and Allen, 1993) and for soybean at 28 to 35C (Jones et al., 1985a). The present model assumes that leaf temperature is equal to air temperature. When the model is used with canopy energy balance and stomatal sensitivity to $\mathrm{CO}_{2}$ and foliage temperature is predicted (Pickering et al., 1990, 1995), the optimum air temperature range becomes even broader because leaf temperature tends to be above air temperature if air temperature is low, and leaf temperature tends to be below air if air temperature is high.

\section{Leaf and canopy photosynthesis response to $\mathrm{CO}_{2}$}

Leaf response to $\mathrm{CO}_{2}$. Figure $8 \mathrm{~A}$ illustrates leaf photosynthesis response to $\mathrm{CO}_{2}$ for leaves at $10,20,30$, and $40 \mathrm{C}$, where the equations include the $\mathrm{CO}_{2}$ effect on electron transport as described above. Photosynthetic response to $\mathrm{CO}_{2}$ increases with temperature. These equations reproduce the well-known increase in $\mathrm{CO}_{2}$ compensation point as temperature increases.

Canopyresponse to $\mathrm{CO}_{2}$. The simulated $\mathrm{P}_{\text {can }}$ response to $\mathrm{CO}_{2}$ in Fig. $8 \mathrm{~B}$ shows that the response to $\mathrm{CO}_{2}$ depends on temperature and is limited at low temperature. The simulated $\mathrm{P}_{\mathrm{can}}$ at $30 \mathrm{C}$ increased $35 \%$ as $\mathrm{CO}_{2}$ increased from 330 to $660 \mathrm{ppm}$. This compares to measured increases in $\mathrm{P}_{\mathrm{can}}$ of $35 \%$ to $40 \%$ for rice (Baker et al., 1992, Boote et al., 1992 ) and $50 \%$ to $60 \%$ for soybean exposed to 660 vs. $330 \mathrm{ppm} \mathrm{CO}$ at 31C (Campbell et al., 1990). Jones et al. (1985b) observed that midday $\mathrm{P}_{\mathrm{can}}$ of soybean measured at $800 \mathrm{ppm} \mathrm{CO} \mathrm{CO}_{2}$ was $75 \%$ greater than the same canopy measured at $330 \mathrm{ppm} \mathrm{CO}_{2}$ (both at $31 \mathrm{C}$ ). Predicted response for that comparison was a $42 \%$ increase. The predicted canopy responses to $\mathrm{CO}_{2}$ in these chambers appear to be somewhat less than those observed.
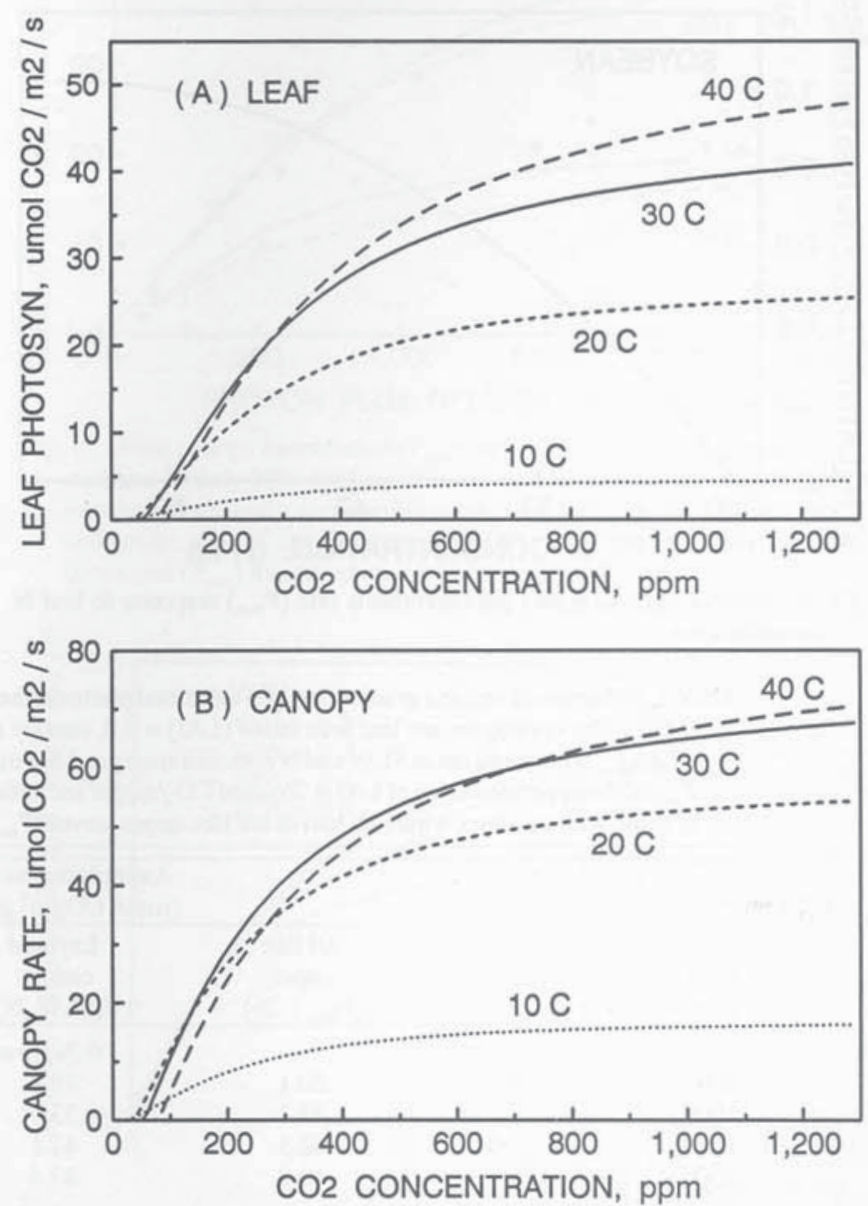

Fig. 8. (A) Leaf photosynthesis and (B) gross canopy assimilation response to $\mathrm{CO}_{2}$ at four temperatures. Response simulated for leaf area index $=5.0$, closed canopy, at a photon flux density of $1500 \mu \mathrm{mol} \cdot \mathrm{m}^{-2} \cdot \mathrm{s}^{-1}$, at solar noon on $1 \mathrm{July}$ at lat. $30^{\circ} \mathrm{N}$, assuming fraction diffuse of 0.49 . Light-saturated photosynthesis rate $\left(\mathrm{P}_{\max }\right)=26 \mu \mathrm{mol} \mathrm{CO} / \mathrm{m}^{2}$ per sec at $350 \mathrm{ppm} \mathrm{CO}$ and $30 \mathrm{C}$. 
$P_{\max }$ as influenced by leaf $\mathrm{N}$ status and growth environment

Under normal conditions, $\mathrm{P}_{\max }, \mathrm{J}_{\max }$, and maximum RuBP carboxylase activity $\left(\mathrm{V}_{\mathrm{cmax}}\right)$ on a leaf-area basis are reasonably well correlated to each other and are proportional to $\mathrm{N}$ concentration, $\mathrm{N}$ content per unit area, chlorophyll concentration, and leaf thickness (Field, 1983; Harley et al., 1992; Seemann et al., 1987). Evans and Farquhar (1991) proposed that $\mathrm{J}_{\max }$ and $\mathrm{P}_{\max }$ are proportional to the chlorophyll and $\mathrm{N}$ content per unit leaf area because these variables reflect the amount of photosynthetic apparatus per unit leaf area. Also, within a species, the amount of rubisco per unit leaf area is proportional to the amount of leaf $N$ per unit leaf area. Sinclair and Horie (1989) proposed that $\mathrm{P}_{\max }$ strongly depends on specific leaf $\mathrm{N}$ content (SLN).

Effects of growth environment (climate, nutrition, and $\mathrm{CO}_{2}$ ) are expressed at the morphological and biochemical level, e.g., SLW, N concentration of leaf tissue, and the amount of chlorophyll, thylakoid membranes, and rubisco per unit leaf area. Second-order environmental effects also occur. The portion of $\mathrm{N}$ in rubisco decreased under $\mathrm{N}$ deficiency and as irradiance declined (Seemann et al., 1987). Decline in total $\mathrm{N}$ per unit leaf mass and decline in rubisco per unit leaf area have been reported in response to increasing $\mathrm{CO}_{2}$ (Harley et al., 1992; Rowland-Bamford et al., 1991). Furthermore, Harley et al. (1992) observed a decline in the ratio of protein allocated to rubisco as $\mathrm{CO}_{2}$ increased.

In our modeling approach, $\mathrm{P}_{\max }$ (at standard $30 \mathrm{C}, 350 \mathrm{ppm} \mathrm{CO}_{2}$, and optimum $\mathrm{N}$ concentration) is allowed to be a linear function of SLW, based on the data of Dornhoff and Shibles (1970), adjusted to $350 \mathrm{ppm}$ $\mathrm{CO}_{2}$, and assuming a zero intercept (zero $\mathrm{P}_{\max }$ at zero SLW, and a $\mathrm{CO}_{2}$ uptake slope of $0.65 \mu \mathrm{mol} \cdot \mathrm{m}^{-2} \cdot \mathrm{s}^{-1}$ per gram leaf mass). $\mathrm{P}_{\max }$ is reduced

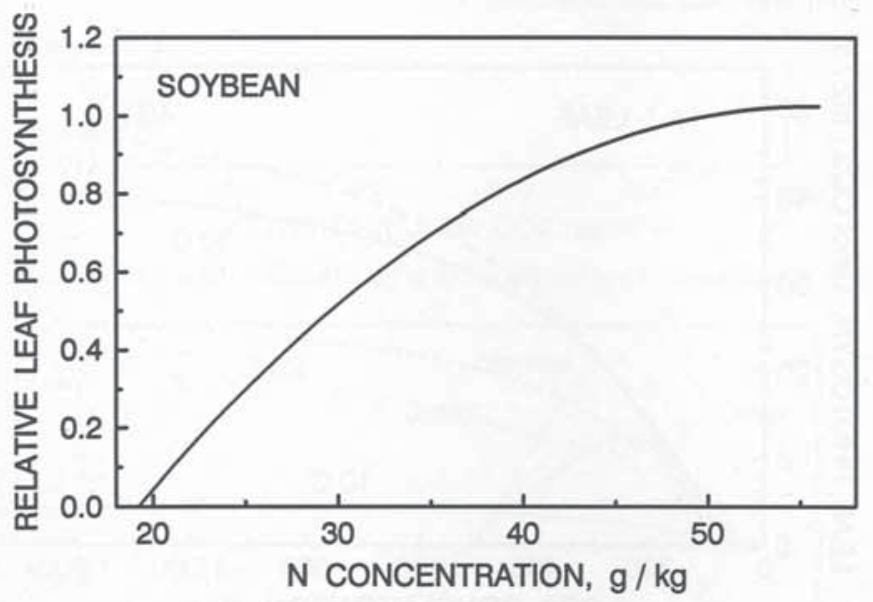

Fig. 9. Relative light-saturated photosynthesis rate $\left(\mathrm{P}_{\max }\right)$ response to leaf $N$ concentration. if $\mathrm{N}$ concentration is not at optimum concentration (Fig. 9) (K.J. Boote, unpublished data).

\section{Variation in $\mathbf{P}_{\max }$, SLW, and $\mathbf{N}$ concentration with LAI depth}

SLW and leaf N concentration vary with depth in the crop canopy and, in turn, influence $P_{\max }$ variation with depth in the canopy. Modeling vertical distribution in leaf photosynthetic characteristics is important for canopy assimilation models (Reynolds et al., 1992). Optimization analysis has shown higher $\mathrm{P}_{\text {can }}$ for closed crop canopies that have higher SLN (and $\mathrm{P}_{\max }$ ) for upper leaf layers at the cost of lower SLN and lower $P_{\max }$ for lower leaf layers (Field, 1983; Hirose and Werger, 1987). Interestingly, crop canopies already tend toward an optimum distribution of SLN and SLW. Shiraiwa and Sinclair (1993) reported that SLN of soybean foliage declined linearly with increasing LAI depth, the slope ranging from 0.19 to $0.29\left(\mathrm{~g} \mathrm{~N} / \mathrm{m}^{2}\right.$ per unit LAI). Using a similar approach, we model decline in SLW and N concentration, each as linear functions of LAI depth. In our simulation examples, SLW declines $3.6 \mathrm{~g} \cdot \mathrm{m}^{-2}$ and $\mathrm{N}$ concentration declines $3.0 \mathrm{~g} \cdot \mathrm{kg}^{-1}$ per unit LAI depth increment. As a result of both features, we obtain variation in $\mathrm{P}_{\max }$ with LAI depth. For simulation purposes, standard light-saturated $\mathrm{P}_{\max }$ is defined at $30 \mathrm{C}$ and $350 \mathrm{ppm} \mathrm{CO}_{2}$ and at a defined SLW $\left(40 \mathrm{~g} \cdot \mathrm{m}^{-2}\right)$ and $\mathrm{N}$ concentration $\left(52 \mathrm{~g} \cdot \mathrm{kg}^{-1}\right)$ for soybean. These values are typical for upper soybean leaves and correspond to the calculated values for the upper third of the LAI of a soybean canopy $(\mathrm{LAI}=5.0)$ when average $\mathrm{SLW}=34 \mathrm{~g} \cdot \mathrm{m}^{-2}$, average $\mathrm{N}$ concentration $=$ $47 \mathrm{~g} \cdot \mathrm{kg}^{-1}$, and SLW and N decline with LAI depth as described above.

For the subsequent simulation examples, the input $\mathrm{P}_{\max }$ is assumed to apply to the upper one-third of the LAI, and $\mathrm{P}_{\max }$ of lower layers declines with LAI depth according to the functions described. In our crop model, canopy average SLW and N concentration are state variables and are used to compute SLW and N of the LAI layers. Layering SLW and $\mathrm{N}$ concentration increases $\mathrm{P}_{\text {can }}$ by $3 \%$ to $8 \%$ over an unlayered, uniform canopy that uses canopy average $\mathrm{P}_{\max }$, SLW, and N (Table 2). Researchers generally measure $P_{\max }$ only for upper, sunlit leaves, which have greater SLW and higher N concentration than the canopy average. These upper leaves are the most relevant ones to measure because upper sunlit leaves receive most of the PFD and generate over half of the canopy $\mathrm{CO}_{2}$ assimilation. Using an input of $\mathrm{P}_{\max }$ for upper leaves and applying it to all LAI depths resulted in only a $1 \%$ to $4 \%$ overestimate of $P_{\text {can }}$. This result could be an argument that vertical gradient in $\mathrm{P}_{\max }$ is not really necessary, provided the input is upper-leaf $P_{\max }$. Definitions of variables and abbreviations are provided in Table 3.

\section{Evaluating the hedgerow photosynthesis model}

Light interception and photosynthesis vs. time of day for closed and incomplete canopies. Crop canopies that are not closed are less able to respond to the high PFD at solar noon when the sun is directly

Table 2. Influence of vertical gradient in light-saturated photosynthesis rate $\left(\mathrm{P}_{\max }\right)$ upon canopy assimilation response to photon flux density $(\mathrm{PFD})$. The conditions are leaf area index $(\mathrm{LAI})=5.0$, canopy average specific leaf weight $(\mathrm{SLW})=34 \mathrm{~g} \cdot \mathrm{m}^{-2}$, and $\mathrm{N}$ concentration $=$ $47 \mathrm{~g} \cdot \mathrm{kg}^{-1}$. The gradients in SLW and N concentration are $3.6 \mathrm{~g} \cdot \mathrm{m}^{-2}$ and $3.0 \mathrm{~g} \cdot \mathrm{kg}^{-1}$ per unit LAI depth increment. For a three-layer canopy, $P_{\max }$ of the upper one-third of LAI is $26 \mu \mathrm{mol} \mathrm{CO} 2 / \mathrm{m}^{2}$ per sec defined at SLW $=40 \mathrm{~g} \cdot \mathrm{m}^{-2}$ and N concentration $=52 \mathrm{~g} \cdot \mathrm{kg}^{-1}$. The comparison is made with canopies where all leaves are like upper leaves $\left(P_{\max }=26\right)$ vs. canopies where all leaves are like average leaves $\left(P_{\max }=21\right)$.

\begin{tabular}{|c|c|c|c|c|c|}
\hline \multirow[b]{2}{*}{$\begin{array}{l}\text { PFD } \\
\left(\mu \mathrm{mol} \cdot \mathrm{m}^{-2} \cdot \mathrm{s}^{-1}\right)\end{array}$} & \multicolumn{3}{|c|}{$\begin{array}{l}\text { Assimilation example } \\
\left(\mu \mathrm{mol} \mathrm{CO}_{2} / \mathrm{m}^{2} \text { per sec }\right)\end{array}$} & \multirow{2}{*}{$\begin{array}{c}\text { Loss if } \\
\text { lower leaf } \\
\mathrm{P}_{\max }<\text { upper } \\
(\%)\end{array}$} & \multirow{2}{*}{$\begin{array}{c}\text { Benefit } \\
\text { from layering } \\
\text { vs. avg } \\
(\%)\end{array}$} \\
\hline & $\begin{array}{c}\begin{array}{c}\text { All like } \\
\text { upper } \\
\left(\mathrm{P}_{\max }=26\right)\end{array} \\
\end{array}$ & $\begin{array}{c}\text { Layered } \\
\text { canopy } \\
\mathrm{f}(\mathrm{SLW}, \mathrm{N})\end{array}$ & $\begin{array}{c}\text { All like } \\
\text { avg } \\
\left(\mathrm{P}_{\max }=21\right)\end{array}$ & & \\
\hline \multicolumn{6}{|c|}{0.245 fraction diffuse } \\
\hline 500 & 20.1 & 19.8 & 19.2 & 1.4 & 3.2 \\
\hline 1000 & 33.3 & 32.5 & 30.8 & 2.5 & 5.5 \\
\hline 1500 & 42.5 & 41.1 & 38.4 & 3.2 & 7.0 \\
\hline 2000 & 49.2 & 47.4 & 43.9 & 3.7 & 7.9 \\
\hline \multicolumn{6}{|c|}{0.490 fraction diffuse } \\
\hline 500 & 20.8 & 20.6 & 20.0 & 0.9 & 3.0 \\
\hline 1000 & 35.5 & 34.9 & 33.1 & 1.7 & 5.2 \\
\hline 1500 & 46.2 & 45.1 & 42.3 & 2.4 & 6.7 \\
\hline 2000 & 54.3 & 52.7 & 48.9 & 3.0 & 7.7 \\
\hline
\end{tabular}


overhead, and a fraction of the PFD is lost directly to the soil. Figures 10 and 11 illustrate how incomplete peanut canopies (92-cm row spacing) intercepted a smaller fraction of the PFD toward midday and tended to light-saturate at a lower PFD than the closed canopies (46$\mathrm{cm}$ row spacing). As the canopy grew wider and increased in LAI, a greater fraction of PFD was intercepted. The diurnal time course of percent light interception (Fig. 10, top) and $P_{\text {can }}$ (Fig. 10, center) are reasonably predicted for the different times of day and treatments. Despite a constant number of plants per square meter in both row spacings, there were persistent row-spacing effects on light interception and $\mathrm{P}_{\text {can }}$ until the widely spaced crop canopy closed at or about 29 July (57 days after planting). The Spitters (1986) function for PFD distribution (Fig. 10, bottom) adequately describes actual PFD mea-
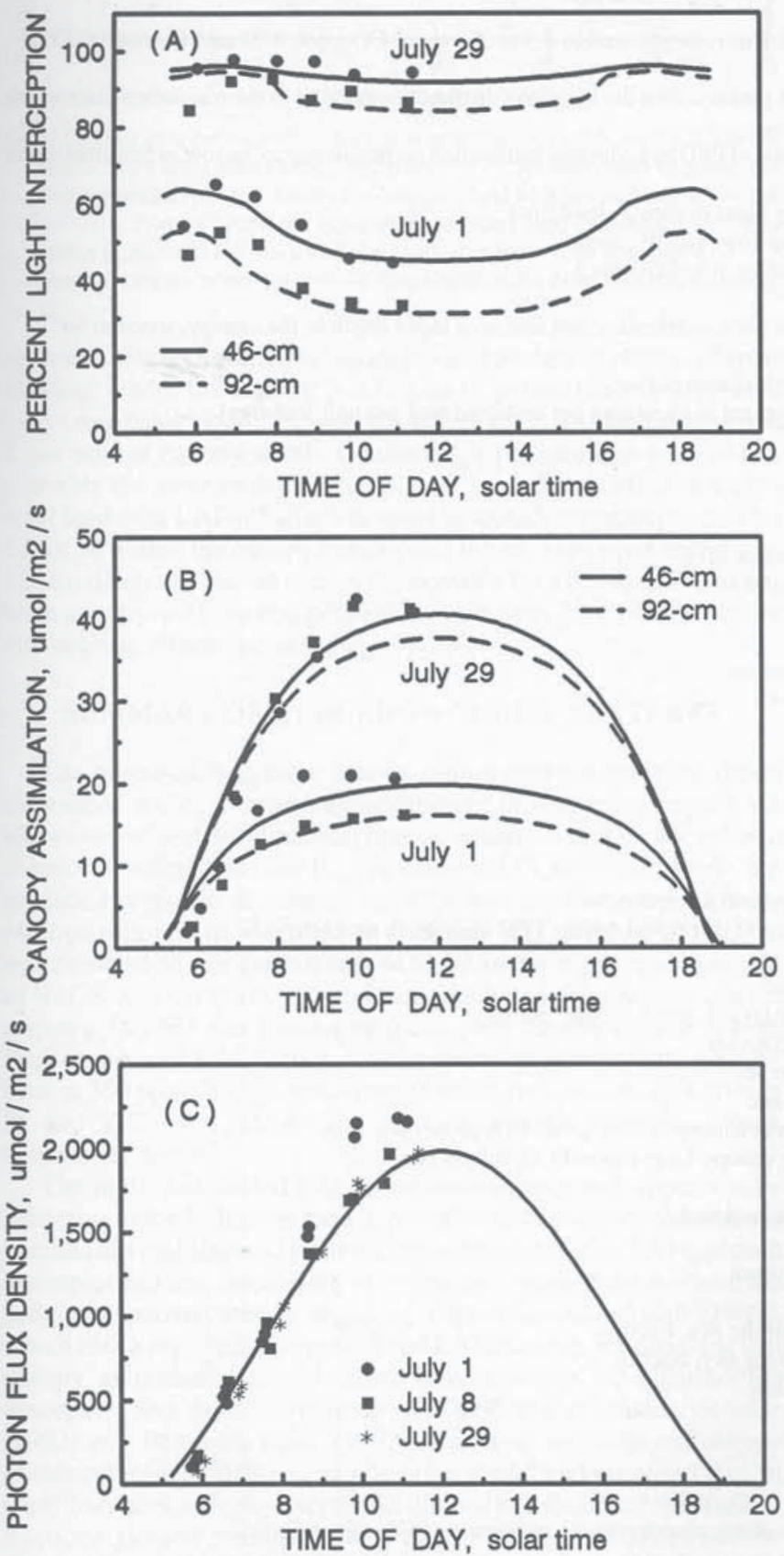

Fig. 10. (A) Light interception, (B) gross canopy assimilation, and (C) photon flux density (PFD) on 1 and 29 July 1987 for peanut canopies in 46- and 92 $\mathrm{cm}$ row spacing as the crop canopy closed. Canopy assimilation was simulated for actual experimental conditions [leaf area index, canopy width and height, and light-saturated photosynthesis rate $\left(\mathrm{P}_{\max }\right)$ measured on sunlit leaves], but using instantaneous PFD from the Spitters function, given a PFD of $58 \mathrm{~mol}^{-d a y^{-1}}$ as input. Solid line for modeled PFD (bottom) is for 1 July. Points represent observed light interception, gross canopy assimilation $\left(\mathrm{P}_{\mathrm{can}}\right)$, and PFD. surements, although it is a bit high near dawn or sunset and a bit low at midday. The alternative full-sine function of Charles-Edwards and Acock (1977) would underpredict near dawn and overpredict at midday. Because $\mathrm{P}_{\mathrm{can}}$ and PFD point measurements were manually taken only for clear sunny conditions, the points are compared to a line predicted for a clear day in July with high daily PFD $\left(58 \mathrm{~mol} \cdot \mathrm{m}^{-2}\right)$ and minimum cloud cover.

Assimilation response to PFD at various degrees of canopy closure. Data for the above measurement dates are plotted in Fig. 11 as $\mathrm{P}_{\mathrm{can}}$ vs. PFD. As expected, the incomplete canopies on 1 July were less able to respond to high PFD, whereas the closed canopies on 29 July increased $\mathrm{P}_{\text {can }}$ to the highest PFD value. The early season row spacing effects on $\mathrm{P}_{\text {can }}$ nearly disappeared with canopy closure. These results show that the hedgerow model will successfully predict canopy assimilation response to PFD for different row spacings, canopy widths, LAIs, times of day, and temperatures, based on only one input ( $\mathrm{P}_{\max }$ measured on upper leaves). We conclude that $\mathrm{P}_{\mathrm{can}}$ can be predicted from single-leaf $\mathrm{P}_{\max }$. Actually, measured peanut $\mathrm{P}_{\max }$ was quite repeatable over seven successive dates in this study and over much of the season in data of Bennett et al. (1993), thus one $P_{\max }$ value could have been used with only a small loss in accuracy.

Daily assimilation response to LAI at various degrees of canopy closure. Figure 12 illustrates the importance of degree of canopy closure on daily assimilation. With $80 \%$ apparent ground cover [width : row spacing $(W: R)=0.8$, there is only a small reduction $(4.2 \%)$ in $\mathrm{P}_{\mathrm{can}}$ even at high LAI. With progressively smaller canopy width (ratio

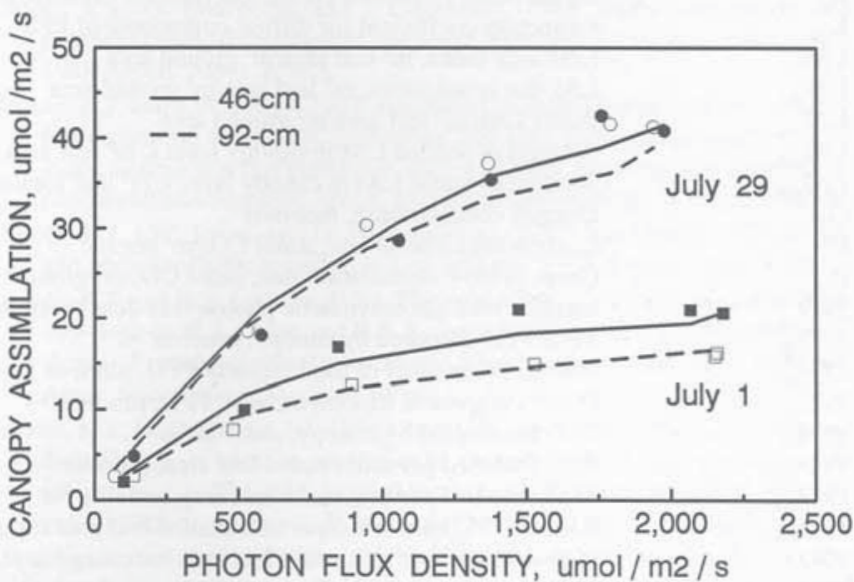

Fig. 11. Gross canopy assimilation $\left(\mathrm{P}_{\text {can }}\right)$ response to photon flux density (PFD) on 1 and 29 July 1987 for peanut in 46 - and $92-\mathrm{cm}$ row spacings. $P_{\text {can }}$ was simulated for actual experimental conditions [leaf area index, canopy width and height, time of day, instantaneous PFD, and light-saturated photosynthesis rate $\left(\mathrm{P}_{\max }\right)$ measured on sunlit leaves].

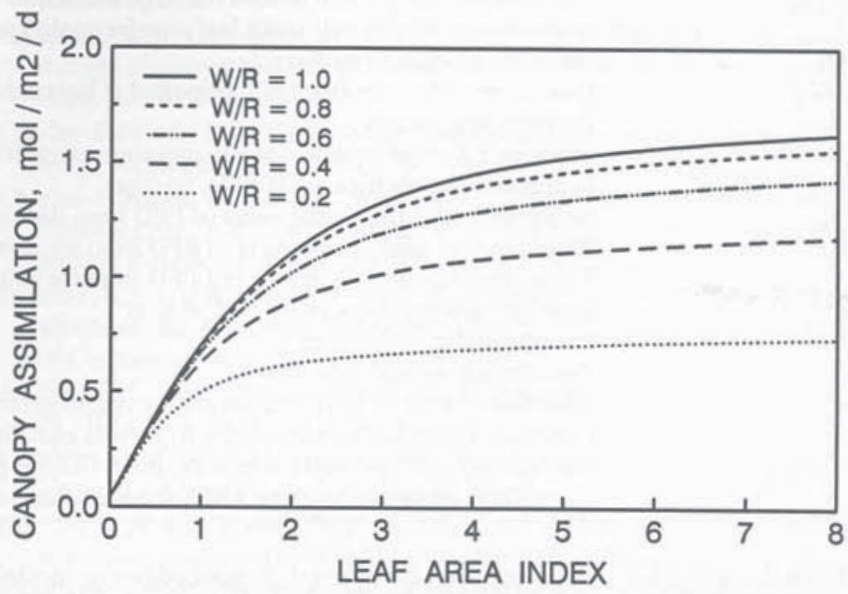

Fig. 12. Daily canopy assimilation vs. leaf area index at five degrees of canopy closure (W/R = canopy width/row spacing). Simulated at $30 \mathrm{C}, \mathrm{CO}_{2}=350$ $\mathrm{ppm}$, light-saturated photosynthesis rate $\left(\mathrm{P}_{\max }\right)=26 \mu \mathrm{mol} \mathrm{CO} / \mathrm{m}^{2}$ per sec, photon flux density $=45 \mathrm{~mol} \cdot \mathrm{m}^{-2} \cdot$ day $^{-1}$, in east-west rows, at lat. $30^{\circ} \mathrm{N}$, on 1 July. 
Table 3. Definition of variables, symbols, and abbreviations used. Fluxes and rates are per square meter of land area, unless clearly stated as per unit leaf area.

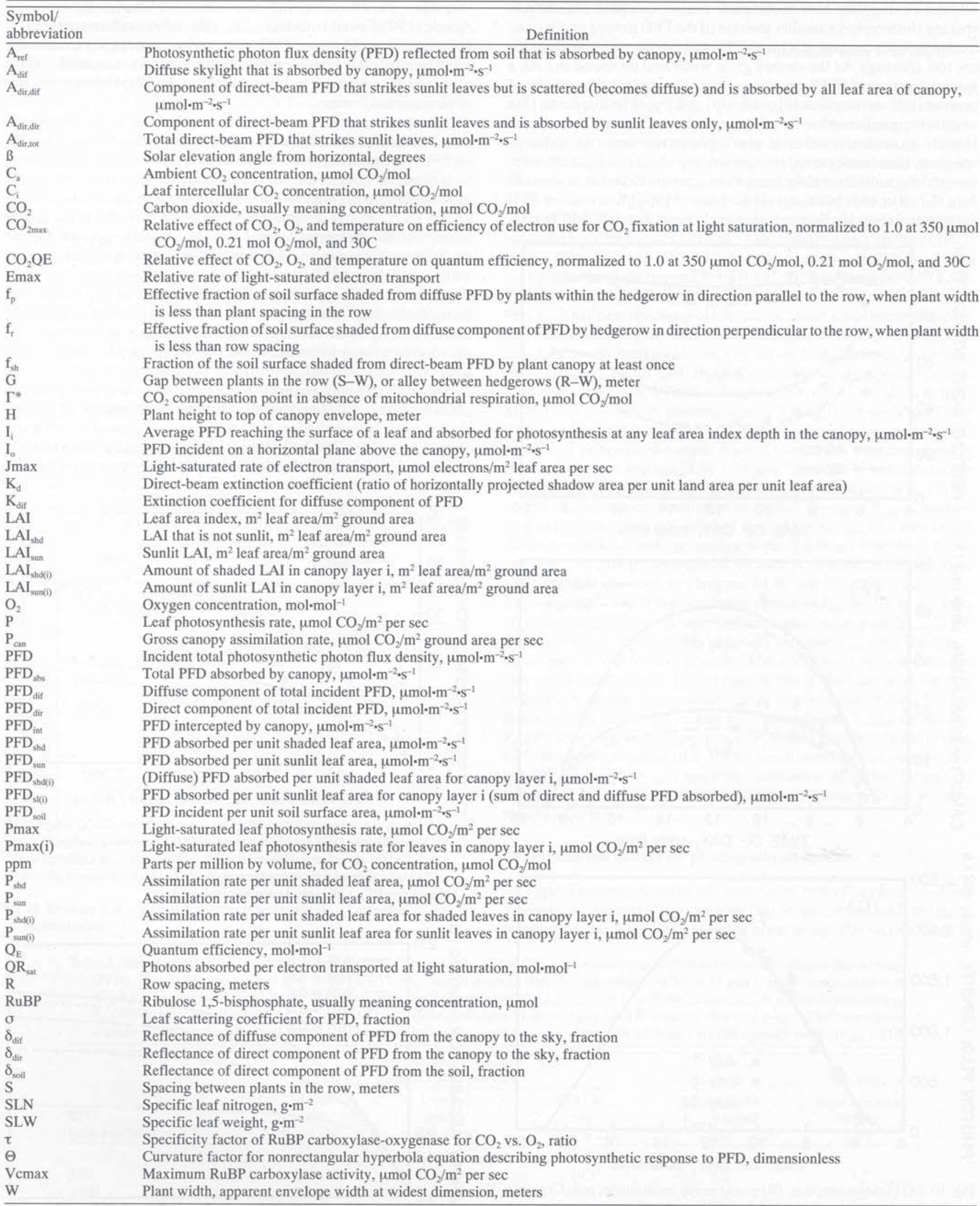

from 0.8 to 0.2$), \mathrm{P}_{\text {can }}$ is progressively reduced. A nonhedgerow model would follow the line for $\mathrm{W}: \mathrm{R}=1.0$ and would be in error by the difference between that line and the line for the given $\mathrm{W}: \mathrm{R}$ ratio. Figure 12 probably gives an overly optimistic impression of photosynthesis at incomplete cover, because it assumes that hedgerows with low W: R ratio can achieve the same land-area LAI as a closed canopy.
The latter is not likely; thus, the reduction in $\mathrm{P}_{\text {can }}$ will be somewhat more than represented in Fig. 12.

Response to row spacing. Figure 13 illustrates response of daily assimilation to variation in row spacing while holding a constant LAI (solid line) or leaf area (LA) per unit of canopy width (long dash line). In conjunction with the crop model, the hedgerow photosynthesis 


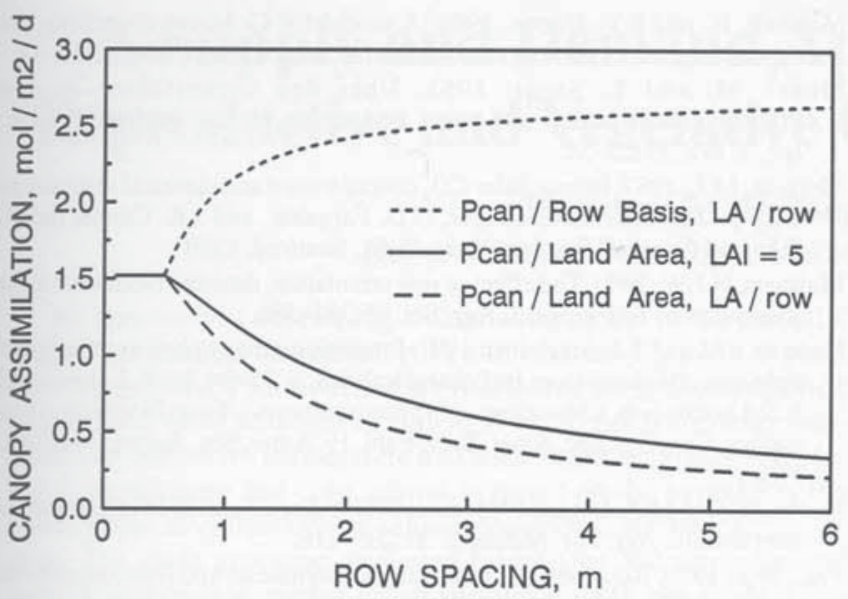

Fig. 13. Daily canopy assimilation vs. row spacing for a crop canopy $0.5 \mathrm{~m}$ tall and $0.5 \mathrm{~m}$ wide. Gross canopy assimilation $\left(\mathrm{P}_{\mathrm{can}}\right)$ is expressed 1$)$ per unit of canopy width (per row basis) for constant LAI of 5 per unit canopy width $(----), 2)$ on a land-area basis with constant land-area-based leaf area index (LAI) of 5 (-), or 3) on land-area basis with constant LAI of 5 per unit canopy width (- - ). Simulated under same conditions as Fig. 12.

approach creates a somewhat more gradual decline in yield at the row spacing, where the canopy just begins to close. The curve labeled "PG / row basis" is the $P_{\text {can }}$ per row where the LA is held constant at 5 per unit of canopy width. Constant LA per unit canopy width is probably the more realistic example, because the situation of a constant land-area LAI of 5 in a 5-m spacing would, for example, force a LA of 50 within the canopy envelope of $0.5 \mathrm{~m}$. The upper line of Fig. 13 also illustrates the maximum $P_{\text {can }}$ possible for a $0.5-m$-tall $\times 0.5-m$ wide canopy with no competition. In this case, lack of a border or competition effects increased $\mathrm{P}_{\text {can }}$ by $77 \%$.

\section{SUMMARY OF HEDGEROW MODEL FEATURES}

The proposed hedgerow canopy photosynthesis approach offers the needed ability to model assimilation of incomplete canopies, yet allows use of leaf-level photosynthesis equations that mimic rubisco kinetics. Predicted leaf and $\mathrm{P}_{\mathrm{can}}$ responses to $\mathrm{CO}_{2}$ were reasonable, but predicted response at subambient $\mathrm{CO}_{2}$ was improved by allowing electron transport to be limited as a function of $\mathrm{C}_{\mathrm{i}}$. Single-leaf $\mathrm{P}_{\max } / \mathrm{J}_{\max }$ was modeled as a linear function of SLW and as a quadratic function of leaf $\mathrm{N}$ concentration. As expected, predicted canopy assimilation response to PFD was limited by incomplete canopies, even at high land-area-based LAI. Canopy assimilation, parameterized for soybean at $350 \mathrm{ppm} \mathrm{CO}$, showed a broad temperature optimum between 25 and $37 \mathrm{C}$, even though leaf $\mathrm{P}_{\max }$ has a more pronounced peak between 32 to $40 \mathrm{C}$.

The sunlit and shaded LAI photosynthesis approach appears to be adaptable to the hedgerow model, provided diffuse-light absorption is handled in a multilayered manner. The sunlit and shaded LAI approach is simpler and less demanding of computer time than the mechanistic hedgerow photosynthesis model of Gijzen and Goudriaan (1989), which uses a ray-tracing approach and LAI layering. We conclude that canopy assimilation models must have layering for diffuse PFD absorption and must have sunlit and shaded leaf classes. Stockle (1992) and Reynolds et al. (1992) compared multilayered canopy photosynthesis models to a single-layer model and proposed that, in many instances, a single-layer model divided into sunlit and shaded LAI fractions yielded reasonable results with $<5 \%$ error. Their results support the sunlit and shaded LAI approach we have taken. Reynolds et al. (1992) confirmed the importance of including leaf energy balance and distinguishing between sunlit and shaded leaves. They provided evidence that a multilayered approach is best. We agree with this need, particularly for diffuse-light absorption. We conclude that the problem with the single-layer models is primarily related to diffuse-light absorption. We also agree with Reynolds et al. (1992) that leaf energy balance is needed. Including an energy balance actually makes the predicted air temperature optimum for photosynthesis even broader in most cases.
Application to horticultural crops. Horticultural commodities are probably grown more often in hedgerow or limited plant spacing than field crops. There are a number of application examples for using such a hedgerow photosynthesis model: 1 ) predicting optimum spacing for fruit and nut tree crops; 2) predicting yield effects of various hedgerow arrangements for trellised vineyards, staked tomatoes, or dwarfed dense hedgerow apples; 3 ) evaluating productivity of sweet corn (Zea mays L.), beans, and potatoes (Solanum tuberosum L.) grown in rows; and 4) evaluating productivity of single plants in response to various spacings in the field and greenhouse.

\section{Literature Cited}

Acock, B., D.A. Charles-Edwards, D.J. Fitter, D.W. Hand, L.J. Ludwig, J. Warren Wilson, and A.C. Withers. 1978. The contribution of leaves from different levels within a tomato crop to canopy net photosynthesis: An experimental examination of two canopy models. J. Expt. Bot. 29:815-827.

Allen, Jr., L.H. 1974. Model of light penetration into a wide-row crop. Agron. J. $66: 41-47$.

Baker, J.T. and L.H. Allen, Jr. 1993. Effects of $\mathrm{CO}_{2}$ and temperature on rice: A summary of five growing seasons. J. Agr. Meteorol. 48:575-582.

Baker, J.T., L.H. Allen, Jr., and K.J. Boote. 1992. Response of rice to $\mathrm{CO}_{2}$ and temperature. Agr. For. Meteorol. 60:153-166.

Bennett, J.M., T.R. Sinclair, L. Ma, and K.J. Boote. 1993. Single leaf carbon exchange and canopy radiation use efficiency of four peanut cultivars. Peanut Sci. 20:1-5.

Boote, K.J., G. Bourgeois, and J. Goudriaan. 1988. Light interception and photosynthesis of incomplete hedgerow canopies of soybean and peanut. 1988 Agron. Abstr. p. 105.

Boote, K.J. and J.W. Jones. 1987. Equations to define canopy photosynthesis from quantum efficiency, maximum leaf rate, light extinction, leaf area index, and photon flux density, p. 415-418. In: J. Biggins(ed.). Progress in photosynthesis research. vol. 4. Martinus Nijhoff Publ., The Netherlands.

Boote, K.J, J.W. Jones, and G. Hoogenboom. 1989. Simulating crop growth and photosynthesis response to row spacing. 1989 Agron. Abstr. p. 11.

Boote, K.J. and R.S. Loomis. 1991. The prediction of canopy assimilation, p. 109-140. In: K.J. Boote and R.S. Loomis (eds.). Modeling crop photosynthesis-From biochemistry to canopy. Crop Sci. Soc. Amer. Spec. Publ.19. Amer. Soc. Agron., Madison, Wis.

Boote, K.J., N. Pickering, J.T. Baker, and L.H. Allen. 1992. Predicting canopy assimilation of rice in response to carbon dioxide concentration and temperature, p. 831-834. In: N. Murata (ed.). Research in photosynthesis. vol. 4. Kluwer Academic Publishers, Dordrecht, The Netherlands.

Brooks, A. and G.D. Farquhar. 1985. Effect of temperature on the $\mathrm{CO}_{2} / \mathrm{O}_{2}$ specificity of ribulose-1,5-bisphosphate carboxylase/oxygenase and the rate of respiration in the light. Estimates from gas-exchange measurements on spinach. Planta 165:397-406.

Campbell, G.S. and J.M. Norman. 1989. The description and measurement of plant canopy structure, p. 1-19. In: G. Russell, B. Marshall, and P.G. Jarvis (eds.). Plant canopies: Their growth, form and function. Cambridge Univ. Press, England.

Campbell, W.J., L.H. Allen, Jr., and G. Bowes. 1990. Response of soybean canopy photosynthesis to $\mathrm{CO}_{2}$ concentration, light, and temperature. J. Expt. Bot. 41:427-433.

Charles-Edwards, D.A. 1981. The mathematics of photosynthesis and productivity. Academic, London.

Charles-Edwards, D.A. and B. Acock. 1977. Growth response of a Chrysanthemum crop to the environment. II. A mathematical analysis relating photosynthesis and growth. Ann. Bot. 41:49-58.

Denison, R.F. and R.S. Loomis. 1989. An integrative physiological model of alfalfa growth and development. Bul. Div. Agr. Natural Resources, Univ. of California, Oakland.

de Wit, C.T. 1965. Photosynthesis of leaf canopies. Agr. Res. Rpt. 663. PUDOC, Wageningen, The Netherlands.

Dornhoff, G.M. and R.M. Shibles. 1970. Varietal differences in net photosynthesis of soybean leaves. Crop Sci. 10:42-45.

Duncan, W.G., R.S. Loomis, W.A. Williams, and R. Hanau. 1967. A model for simulating photosynthesis in plant communities. Hilgardia 38:181-205.

Ehleringer, J. and O. Björkman. 1977. Quantum yields for $\mathrm{CO}_{2}$ uptake in $\mathrm{C}_{3}$ and $\mathrm{C}_{4}$ plants: Dependence on temperature, $\left[\mathrm{CO}_{2}\right]$, and $\left[\mathrm{O}_{2}\right]$ concentration. Plant Physiol. 59:86-90.

Ehleringer, J. and R.W. Pearcy. 1983. Variation in quantum yield for $\mathrm{CO}_{2}$ uptake among $\mathrm{C}_{3}$ and $\mathrm{C}_{4}$ plants. Plant Physiol. 73:555-559.

Erbs, D.G., S.A. Klein, and J.A. Duffie. 1982. Estimation of the diffuse 
radiation fraction for hourly, daily and monthly-average global radiation. Solar Energy 28:293-302.

Evans, J.R. and G.D. Farquhar. 1991. Modeling canopy photosynthesis from the biochemistry of the $\mathrm{C}_{3}$ chloroplast, p. 1-15. In: K.J. Boote and R.S. Loomis (eds.). Modeling crop photosynthesis-From biochemistry to canopy. Crop Sci. Soc. Amer. Spec. Publ. 19. Amer. Soc. Agron., Madison, Wis.

Farquhar, G.D. and S. von Caemmerer. 1982. Modelling of photosynthetic response to environment, p. 549-587. In: O.L. Lange, P.S. Nobel, C.B. Osmond, and H. Ziegler (eds.). Encyclopedia of plant physiology. new series. vol. 12B. Physiological plant ecology II. Springer-Verlag, Berlin.

Farquhar, G.D., S. von Caemmerer, and J.A. Berry. 1980. A biochemical model of photosynthetic $\mathrm{CO}_{2}$ assimilation in leaves of $\mathrm{C}_{3}$ species. Planta 149:7890.

Field, C. 1983. Allocating leaf nitrogen for the maximization of carbon gain: Leaf age as a control on the allocation program. Oecologia (Berlin) 56:341347.

Gijzen, H. and J. Goudriaan. 1989. A flexible and explanatory model of light distribution and photosynthesis in row crops. Agr. For. Meteorol. 48:1-20.

Goudriaan, J. 1977. Crop micrometeorology: A simulation study. Centre for Agricultural Publishing and Documentation, Wageningen, The Netherlands.

Goudriaan, J. 1982. Potential production processes, p. 98-113. In: F.W.T. Penning de Vries and H.H. van Laar (eds.). Simulation of plant growth and crop production. Centre for Agricultural Publishing and Documentation, Wageningen, The Netherlands.

Goudriaan, J. 1986. A simple and fast numerical method for the computation of daily totals of crop photosynthesis. Agr. For. Meteorol. 38:249-254.

Goudriaan, J. 1988. The bare bones of leaf-angle distribution in radiation models for canopy photosynthesis and energy exchange. Agr. For. Meteorol. 43:155-169.

Harley, P.C. and J.D. Tenhunen. 1991. Modeling the photosynthetic response of $\mathrm{C}_{3}$ leaves to environmental factors, p. 17-39. In: K.J. Boote and R.S. Loomis (eds.). Modeling crop photosynthesis-From biochemistry to canopy. Crop Sci. Soc. Amer. Spec. Publ. 19. Amer. Soc. Agron., Madison, Wis.

Harley, P.C., R.B. Thomas, J.F. Reynolds, and B.R. Strain. 1992. Modelling photosynthesis of cotton grown in elevated $\mathrm{CO}_{2}$. Plant Cell Environ. $15: 271-282$.

Harley,P.C., J.A. Weber, and D.M. Gates. 1985. Interactive effects of light, leaf temperature, $\left[\mathrm{CO}_{2}\right]$ and $\left[\mathrm{O}_{2}\right]$ on photosynthesis in soybean. Planta 165:249263.

Hirose, T. and M.J.A. Werger. 1987. Maximizing daily canopy photosynthesis with respect to the leaf nitrogen allocation pattern in the canopy. Oecologia (Berlin) 72:520-526.

Hoogenboom, G., J.W. Jones, and K.J. Boote. 1992. Modeling growth, development, and yield of grain legumes using SOYGRO, PNUTGRO, and BEANGRO: A review. Trans. Amer. Soc. Agr. Eng. 35:2043-2056.

Johnson, I.R. and J.H.M. Thornley. 1984. A model of instantaneous and daily canopy photosynthesis. J. Theoretical Biol. 107:531-545.

Jones, P., L.H. Allen, Jr., and J.W. Jones. 1985a. Responses of soybean canopy photosynthesis and transpiration to whole-day temperature changes in different $\mathrm{CO}_{2}$ environments. Agron. J. 77:242-249.

Jones, P., L.H. Allen, Jr., J.W. Jones, and R. Valle. 1985b. Photosynthesis and transpiration responses of soybean canopies to short- and long-term $\mathrm{CO}_{2}$ treatments. Agron. J. 77:119-126.

Jordan, D.B. and W.L. Ogren. 1984. The $\mathrm{CO}_{2} / \mathrm{O}_{2}$ specificity of ribulose $1,5-$ bisphosphate carboxylase/oxygenase. Dependence on ribulose-bisphosphate concentration, $\mathrm{pH}$, and temperature. Planta 161:308-313.

Kimball, B.A. and L.A. Bellamy. 1986. Generation of diurnal solar radiation, temperature, and humidity patterns. Energy Agr. 5:185-197.

Long, S.P. 1991. Modification of the response of photosynthetic productivity to rising temperature by atmospheric $\mathrm{CO}_{2}$ concentrations: Has its importance been underestimated? Plant Cell Environ. 14:729-739.

Loomis, R.S. and W.A. Williams. 1969. Productivity and the morphology of crop stands: Patterns with leaves, p. 27-51. In: J.D. Eastin, F.A. Haskins, C.Y. Sullivan, and C H.M. Van Bavel (eds.). Physiological aspects of crop yield. Amer. Soc. Agron., Madison, Wis.
Marshall, B. and P.V. Biscoe. 1980. A model for $\mathrm{C}_{3}$ leaves describing the dependence of net photosynthesis on irradiance. J. Expt. Bot. 31:29-39.

Monsi, M. and T. Saeki. 1953. Über den Lickhtfaktor in den Pflanzengesellschaften und seine Bedeutung für die Stoffproduktion. Jpn. J. Bot. 14:22-52.

Morison, J.I.L. 1987. Intercellular $\mathrm{CO}_{2}$ concentration and stomatal response to $\mathrm{CO}_{2}$, p. 229-251. In: E. Zeiger, G.D. Farquhar, and I.R. Cowan (eds.). Stomatal function. Stanford Univ. Press, Stanford, Calif.

Mutsaers, H.J.W.1980. The effect of row orientation, date and latitude on light absorption by row crops. J. Agr. Sci. 95:381-386.

Norman, J.M. and T.J. Arkebauer. 1991. Predicting canopy photosynthesis and light-use efficiency from leaf characteristics, p. 75-94. In: K.J. Boote and R.S. Loomis (eds.). Modeling crop photosynthesis-From biochemistry to canopy. Crop Sci. Soc. Amer. Spec. Publ. 19. Amer. Soc. Agron., Madison, Wis.

Parton, W.J. and J.A. Logan. 1981. A model for diurnal variation in soil and air temperature. Agr. For. Meteorol. 23:205-216.

Peat, W.E. 1970. Relationships between photosynthesis and light intensity in the tomato. Ann. Bot. 34:319-328.

Pickering, N.B., J.W. Jones, and K.J. Boote. 1990. A moisture- and $\mathrm{CO}_{2}-$ sensitive model of evapotranspiration and photosynthesis. Paper 90-2519. Amer. Soc. Agr. Eng., St. Joseph, Mich.

Pickering, N.B., J.W. Jones, and K.J. Boote. 1995. Adapting SOYGRO V5.42 for prediction under climate change conditions. In: C. Rosenzweig, S. Hollinger, J. Jones, and L. Harper (eds.). Climate change in agriculture: Analysis of potential international impacts. Spec. Publ., Amer. Soc. Agron., Madison, Wis. (In press.)

Rastetter, E B., A.W. King, B.J. Cosby, G.M. Hornberger, R.V. O'Neill, and J.E. Hobbie. 1992. Aggregating fine-scale ecological knowledge to model coarser-scale attributes of ecosystems. Ecol. Applications 2:55-70.

Reynolds, J.F. and B. Acock. 1985. Modeling approaches for evaluating vegetation responses to carbon dioxide concentration, p. 33-51. In: B.R. Strain and J.D. Cure (eds.). Direct effects of increasing carbon dioxide on vegetation. U.S. Dept. of Energy, Carbon Dioxide Res. Div., DOE/ER0283, Washington, D.C.

Reynolds, J.F., J. Chen, P.C. Harley, D.W. Hilbert, R.L. Dougherty, and J.D, Tenhunen. 1992. Modeling the effects of elevated $\mathrm{CO}_{2}$ on plants: Extrapolating leaf response to a canopy. Agr. For. Meteorol. 61:69-94.

Ross, J. 1981. The radiation regime and architecture of plant stands. Tasks for vegetative sciences. no. 3. Dr. W. Junk, The Hague, The Netherlands.

Rowland-Bamford, A.J., J.T. Baker, L.H. Allen, Jr., and G. Bowes. 1991. Acclimation of rice to changing atmospheric carbon dioxide concentration. Plant Cell Environ. 14:577-583.

Seemann, J.R., T.D. Sharkey, J.L. Wang, and C.B. Osmond. 1987. Environmental effects on photosynthesis, nitrogen-use-efficiency, and metabolite pools in leaves of sun and shade plants. Plant Physiol. 84:796-802.

Sharkey, T.D., J.A. Berry, and R.F. Sage. 1988. Regulation of photosynthetic electron-transport in Phaseolus vulgaris L., as determined by room-temperature chlorophyll $a$ fluorescence. Planta 176:415-424.

Shiraiwa, T. and T.R. Sinclair. 1993. Distribution of nitrogen among leaves in soybean canopies. Crop Sci. 33:804-808.

Sinclair, T.R. and T. Horie. 1989. Leaf nitrogen, photosynthesis, and crop radiation use efficiency: A review. Crop Sci. 29:90-98.

Spitters, C.J.T. 1986. Separating the diffuse and direct component of global radiation and its implication for modeling canopy photosynthesis. Part II. Calculation of canopy photosynthesis. Agr. For. Meteorol. 38:231-242.

Spitters, C.J.T., H.A.J.M. Toussaint, and J. Goudriaan. 1986. Separating the diffuse and direct component of global radiation and its implications for modeling canopy photosynthesis. I. Components of incoming radiation. Agr. For. Meteorol. 38:217-229.

Stockle, C.O. 1992. Canopy photosynthesis and transpiration estimates using radiation interception models with different levels of detail. Ecol. Modelling 60:31-44.

Tenhunen, J.D., J.A. Weber, C.S. Yocum, and D.M. Gates. 1976. Development of a photosynthesis model with an emphasis on ecological applications. II. Analysis of a data set describing the $P_{m}$ surface. Oecologia 26:101-109.

Wagner, H.M. 1969. Principles of operations research. Prentice-Hall, Englewood Cliffs, N.J. 